\title{
CONTRA LA HÍPER-CONSTITUCIÓN COLONIAL DE LOS DERECHOS FUNDAMENTALES, EN BÚSQUEDA DE UN NÚCLEO INTERCULTURAL COMPARTIDO $^{1}$
}

\author{
LUCIO PEGORARO \\ Catedrático de Derecho público comparado \\ Universidad de Bolonia
}

TRC, n. ${ }^{\circ} 47,2021$, pp. $97-127$

ISSN 1139-5583

\begin{abstract}
SUMARIO
I. Premisa. II. La deconstrucción de las fuentes y la invención de las híper-fuentes: III. La elaboración del núcleo duro en el derecho euro-atlántico. IV. La defensa del núcleo. V. El lado obscuro de la fuerza: las aspiraciones imperiales del constitucionalismo contemporáneo (y de la jurisprudencia constitucional e internacional). VI. En búsqueda de un denominador común y la formulación de un núcleo compartido y no impuesto. VII. Conclusiones.
\end{abstract}

\section{PREMISA}

A través de este ensayo pretendemos plantear algunas críticas al denominado occidentalismo jurídico y denunciar el apoyo ofrecido por los enfoques universalistas al derecho público/constitucional, basados en los derechos fundamentales/ humanos y la dignidad, frente al ataque que la globalización desarrolla contra el pluralismo social, cultural, político, económico y jurídico. Trataremos de desarrollar así una propuesta alternativa de «núcleo duro» constitucional, compartido por varias culturas y tradiciones jurídicas, y no centrada exclusivamente en los derechos.

1 Artículo escrito en el marco del PRIN 2017 «From Legal Pluralism to the Intercultural State. Personal Law, Exceptions to General Rules and Imperative Limits in the European Legal Space» (CUP J34I19004200001). Trad. M.C. Contreras CortÉs. 
La construcción de la globalización en declinación «euro-atlántica» ${ }^{2}$, ofrecida por la doctrina constitucionalista, se traduce, en una primera fase, en la elaboración de un núcleo de valores absolutos, que reconduce a una única Grundnorm el pluralismo occidental, dando estructura jurídica a una híper-constitución de construcción docta y jurisprudencial, resistente a cualquier modificación incluso súper-mayoritaria. En una segunda fase, implica la atribución a la Grundnorm de un valor global, a través de la circulación/imposición doctrinal de una versión actualizada pero distorsionada del constitucionalismo, y su sanción positiva, a través del derecho de los tratados y transnacional, encomendada sobre todo a las jurisdicciones internacionales y regionales, y a las jurisdicciones constitucionales internas.

Dentro de los sistemas euro-atlánticos, la doctrina trabaja en sinergia con los formantes socio-político, económico, y jurídico-normativo, dándoles legitimación. La Grundnorm elaborada por los profesores es la descrita por la economía, por la (retracción de la) política, por la sociedad sin los cuerpos intermedios, por el énfasis sobre el individuo aislado, por la traslación de los poderes de decisión a órganos carentes de representatividad y de control. Los profesores participan en ella asumiéndola como norma de conducta y, por tanto, consideran el derecho como ciencia prescriptiva ${ }^{3}$.

Fuera de los sistemas euro-atlánticos, para justificar su elaboración y apoyo, la doctrina se ve obligada a una fictio: ignorando los hechos, y descartando cualquier visión descriptiva del derecho, afirma que la Grundnorm vincula a todos; de esta manera, participa en la elaboración de un derecho impuesto ${ }^{4}$, desconectado de la realidad empíricamente demostrable y, por lo tanto, desempeña funciones de política del derecho.

Aceptar o no aceptar la norma fundamental (y entonces estudiar desde una perspectiva interna o externa al ordenamiento) es de hecho, problema de quien vive, forja, interpreta, estudia aquel ordenamiento. Como lo recuerda Scarpelli, el

2 Acojo la calificación de R. ToniatTi, «Per una concezione aperta, plurale ed eterodossa del metodo comparato nel diritto costituzionale», DPCE online, n. 42 (1) 2020, p. 836, y de M. Bussani, Il diritto dell'Occidente. Geopolitica delle regole globali, Einaudi, Torino, 2010, p. XII, según la cual los argumentos con los que Occidente, máximo artífice de la ley global, se enfrenta a otras experiencias y tradiciones jurídicas «son modalidades y argumentos que a menudo parten del supuesto de que sólo nosotros tenemos el derecho, mientras que los demás sólo intentan imitarnos o estúpidamente resistirnos». El jurista occidental prefiere continuar usando, a pesar de los cambios que se están dando, una dimensión etnocéntrica de los ordenamientos como una práctica puramente euroatlántica.

3 Barreto, J.M., «Eurocentric and Third-World Histories of Human Rights: Critique, Recognition and Dialogue», BARreto, J.M. (ed), Human Rights from a Third World Perspective: Critique, History and International Law, Cambridge Scholars Publ., Newcastle upon Tyne, 2013, p. 160, «questions the reliability and universality of the Western historiography and argues in favour of the legitimacy of Third-World histories of human rights elaborated in the context of modern colonialism». De este mismo autor v. también «Decolonial Thinking and the Quest for Decolonising Human Rights», Asian Journ. soc. Sc., n. ${ }^{\circ} 46$ (4-5), 2018.

4 Remito a mi trabajo «Constituciones (y reformas constitucionales) «impuestas» o «condicionadas» (para una re-clasificación interdisciplinaria de la categoría)», Escuredo Rodríguez, R., CANo Bueso, J. (eds.), Crisis económica y modelo social: la sostenibilidad del Estado de bienestar, Un. de Almería, Almería, 2013, p. 75 ss. 
problema de la existencia de la norma fundamental es diferente de la cuestión de su aceptación ${ }^{5}$. Sin embargo, es diferente sólo para el jurista interno (incluido el teórico general), mientras para aquellos que manejan más ordenamientos desde una perspectiva comparada no puede serlo, a menos de considerar como parámetro una única norma base, tratándose más bien de un mero acierto empírico, y no «de elección, de toma de posición, de aplicaciones de normas y valores metajurídicos» ${ }^{6}$.

El punto de vista «interno» respecto a las normas es el de quien las asume, respecto a un ordenamiento jurídico, como «una guía de la conducta y criterio de valor», para quien las mira desde el punto de vista «externo», «la experiencia es concebida como conjunto de hechos, ligados por relaciones causales, dialécticas, etc.»; el punto de vista interno puede ser y suele ser adoptado, además, por «buenos ciudadanos o súbidtos fieles», de los juristas que «aceptan aquellas normas y las exponen desde la cátedra y en los escritos doctrinarios» ${ }^{7}$, pero que operan dentro de un determinado ordenamiento. Juristas por lo tanto de las ciencias internas, «del ordenamiento», no comparatistas. O bien — y es nuestro caso- juristas, teóricos y filósofos convencidos de que la norma fundamental es verdaderamente una sola para todos ${ }^{8}$.

Para estas corrientes predominantes, no hay diferenca entre estudiar el propio ordenamiento, un ordenamiento más amplio anclado a un mismo sistema de valores, principios, tradiciones, economía, sociedad (la «tradición jurídica occidental» ${ }^{9}$ ), y considerar el mundo entero en sus poliédricas manifestaciones. De hecho, el derecho comparado se usa a menudo de manera instrumental precisamente para demostrar estas verdades «universales».

Puede ser extendida a este tipo de acercamiento al derecho constitucional/ público comparado la crítica que Guastini formula a los críticos del realismo: ellos, «aparentemente, no están interesados en el (mero) conocimiento del derecho, y por lo tanto de las prácticas interpretativas que, del Derecho, son una parte constituyente. Lo que les interesa es sólo participar en la práctica jurídica «desde un punto de vista interno». Digámoslo así: la ciencia jurídica definitivamente prefiere la política antes que la ley. En lugar de describir imparcialmente el Derecho, prefiere

5 Scarpelli, U., «Voz Metodo giuridico», en Grifo, C. (ed), Enc. Feltrinelli Fisher. Diritto 2 (G. Crifò -ED-), Milano, 1972, p. 419 ss. y esp. p. 420; y en Grifo, C. (ed), L'etica senza verità, il Mulino, Bologna, 1982.

6 Ibid.

7 Ibid, p. 418 s.

8 Sobre las visiones antitéticas de los comparatistas v. Somma, A., Introduzione al diritto comparato, 2. ${ }^{\mathrm{a}}$ ed., Giappichelli, Torino, 2019, p. 3 ss. y espec. 6 s.

9 Sobre la existencia y las carácteristicas de una tradición jurídica occidental, Berman, H.J., Law and Revolution: The Formation of the Western Legal Tradition, Harvard U.P., Cambridge, 1983, KELLY, J.M., A Short History of the Western Legal Theory, Clarendon, Oxford, 1992. Sobre las raíces occidentales (anglo-americanas) del derecho global v. Sснмітт, C., Acceleratori involontari. Ovvero: la problematica dell'emisfero occidentale (1942), Stato, Grande Spazio, Nomos (G. Marschke, ed.). De hecho, el «centro propulsor [...] es Europa — en particular Europa atlántica», «aúnque en el s XV China pudiera ser el candidado natural para dominar y colonizar el resto del mundo»: cfr. ORTINO, S., La struttura delle rivoluzioni economiche, Cacucci, Bari, 2010, p. 384 s. 
(contribuir a) hacerlo» ${ }^{10}$. $\mathrm{Y}$ además: «Una norma fundamental condicionada por una definición de «Derecho» iusnaturalista, claramente no sirve para la descripción de la ley positiva vigente. Solo puede cumplir tareas de política del Derecho: acreditar las normas que se ajustan a la ley natural como vinculantes, desacreditar las normas que no se ajustan a ellas como no vinculantes. El discurso jurisprudencial de los iusnaturalistas no tiene nada genuinamente descriptivo» ${ }^{11}$.

\section{LA DECONSTRUCCIÓN DE LAS FUENTES Y LA INVENCIÓN DE LAS HÍPER-FUENTES}

La coherencia de la doctrina con los formantes «no jurídicos» de la globalización pasa por la contrucción de una híper-constitución metafísica transnacional, basada en los derechos humanos (o fundamentales, o constitucionales) de imprinting occidental ${ }^{12} \mathrm{y}$ en la división de los poderes como única estructura admisible del frame of government ${ }^{13}$. Las tomas de distancia — que a menudo hayde los perfiles más llamativamente lejanos de la legitimación popular no oculta la sustancial obra de soporte al diseño imperial de un derecho único (la raison du plus fort), a través del apoyo de la híper-constitución a las pretensiones hegemónicas de la economía y (con mucho más esfuerzo) de la política.

Mientras las constituciones las escriben sus constituyentes, las reformas constitucionales los órganos habilitados por la constitución, y las leyes los legisladores, la híper-constitución la escriben, avalados por la doctrina que llaman como apoyo, los jueces constitucionales y transnacionales, a los cuales la doctrina confía con entusiasmo esta tarea ${ }^{14}$. La conjunción entre (parte de la) doctrina y jurisdicciones constitucionales (y transnacionales), genera una nueva fuente de legitimación de los

10 Guastini, R., «Ermeneutici e analitici», parte II, cap. II, § de JD, Discutendo, M. Pons, Madrid, 2017, p. 225.

11 Guastini, R., «Problemi concettuali del normativismo», parte I, cap. X, § 1, de ID., Discutendo, cit., p. 126.

12 Sobre la vagüedad de la categoría, su connotación ideológica y la confusión terminológica reenvío a Pegoraro, L., Delgado Gaitan, J., «Derechos «fundamentales»: consideraciones sobre la elaboración del concepto y su implicación positiva en el contexto del constitucionalismo contemporáneo», Rev. Der. del Estado, 2001, n. ${ }^{\circ}$ 10, p. 41ss; PegOraro, L., Ensayos sobre justicia constitucional, la descentralización y las libertades, Porrúa, México, 2006, p. 289 ss, Pegoraro, L., Metodología y modelos por una investigación sobre derechos fundamentales (con especial referencia a las transicciones constitucionales), AA.VV., Ponencias Desarrolladas del IX Congreso Nacional de Derecho Constitucional, Adrus, Arequipa, 2008, p. 3 ss.

13 Sobre la elaboración de la híper-constitución v. Pegoraro, L., Rinella, A., Costituzioni e fonti del diritto, Giappichelli, Torino, 2018, p. 128 ss. trad. esp. Constituciones y fuentes del derecho, en ID. (eds), Derecho constitucional comparado, t III, Constituciones y fuentes del derecho, Giapichelli, Torino - Astrea, Buenos Aires-Bogotá-Porto Alegre, 2019.

14 Observa Ragone, S., «The «Basic Structure» of the Constitution as an Enforceable Yardstick in Comparative Constitutional Adjudication», Rev. est. const., hermenêtica e teoria do dir. (RECHTD), $\mathrm{n} .{ }^{\circ} 11$ (3) 2019, p. 327 ss., que el núcleo duro es, sin embargo, determinado por el formante jurisprudencial, indipendentemente de las cláusolas concretas insertas en la constitución. 
sistemas jurídicos del mundo, que condiciona toda la producción jurídica y que traduce el activismo judicial de «dictatura comisaria», autorizada democráticamente, a «dictatura soberana», autorizada solo por sí misma y por otro «poder» no democrático, la doctrina ${ }^{15}$. Ello no sólo en áreas juridico-culturales donde no hay fractura entre formante cultural y formantes jurídicos, sino también — con reclamos hegemónicos, y a veces, mera aceptación- donde el desprendimiento sea profundo y arraigado en los siglos.

Los valores meta-democráticos se buscan hoy no en una síntesis de valores compartidos por las diversas culturas que los forjan («deber», «moral», «armonía», «religión», «naturaleza», «familia», «tribu», «perdón», «ocio», «tradición», «corrección», «comunidad», «deferencia», «felicidad» ${ }^{16}$ ), más nuestros derechos fundamentales/ humanos y la dignidad, sino sólo en los derechos fundamentales/humanos y la dignidad, con desprecio arrogante de incorporar otros en el denominador comun ${ }^{17}$.

En discusión no está sólo la idea dogmática de los derechos fundamentales, es decir el derecho de cada comunidad de elegir, entre los derechos, aquellos que consideren predominantes (o «fundamentales»), sino la idea teorética de que éstos pre-existen y son iguales para todos, independientemente de las decisiones tomadas en cada caso por ellas.

En el plano epistemológico, presuponer derechos fundamentales universales, no anclados a las elecciones axiológicas de cada sociedad, implica: desconocer el conocimiento empírico y dar connotaciones religiosas a preferencias condicionadas ineludiblemente por la cultura de pertenencia ${ }^{18}$; negar la enseñanza de la historia y de otras ciencias, como la sociología, la antropología, la geografía, la ciencia política ${ }^{19}$; además, poner la ciencia a disposición de usos partidistas, para avalar decisiones políticas

15 Obviamente se hace referencia aquí a Schmiтt, C., Die Diktatur. Von den Anfängen des modernen Souveränitätsgedankens bis zum proletarischen Klassenkampf, Duncker \& Humblot, München-Leipzig, 1921.

16 Para un análisis del impacto de los estudios sobre la felicidad en las elecciones de política del derecho cfr. Huang, P.H., "Happiness Studies and Legal Policy», Annual rev. of law and soc. sc., n. ${ }^{\circ}$ 6, 2010, p. 405 ss., y Graziadei, M., Pasa, B., «Happiness Once More», Journ. comp. law, n. ${ }^{\circ} 14$ (2), 2019, p. 203 ss.

17 La síntesis propuesta por la alianza doctrina-jurisprudencia es la «cédula» de Carlos V evocada por Lanni, S., «Voz Sistema giuridico latinoamericano», Dig. priv., Sez. civ., Agg., Utet, Torino, 2016, p. 720: una doctrina que de desde 1530 no ha avanzado un paso, con la cual se establecía que «los gobernadores, y justicias reconozcan con particular atención la orden, y forma de vivir de los indios, policía, y disposición en los mantenimientos, y avisen a los Vicerreyes, o Audiencias, y guarden a sus buenos usos, y costumbres en lo que no fueren contra nuestra sagrada religión». Véase también ID., Il diritto nell'America Latina, Esi, Napoli, 2017.

18 Critica este tipo de enfoque S. BAGNI, Dal Welfare State al Caring State?, Dallo Stato del bienestar allo Stato del buen vivir. Innovazione e tradizione nel costituzionalismo latino-americano, Filodiritto, Bologna, 2013, p. 25 , quien observa que «El problema no es de contenido, sino de método, en cuanto se impone interpretar una cultura y una tradición jurídica a través de parámetros propios de otra, a menudo completamente incompatibles entre sí».

19 Pegoraro, L., Diritto, diritto comparato, altre scienze nello studio del nuevo constitucionalismo andino e del buen vivir, en BALDIN, S., ZAGO, M. (eds.), Le sfide della sostenibilità. Il buen vivir andino dalla prospettiva europea, Filodiritto, Bologna, 2014, p. 389 ss.; «Comparación jurídica y uso «externo» de las otras ciencias», Rev. jur. Avances, n. ${ }^{\circ}$ 7, 2012, p. 295 ss., y en Moccia, L., et al. (eds), Estudios de Derecho Civil. Derecho comparado, Derecho Híbrido, Derechos Humanos, Ciencia Política, Upica, Lima-Bogotá-Panamá, 2014, p. 437 ss. 
que utilizan la defensa de los derechos (y de la democracia) para ocultar otros fines (salvo en ocasiones lamentar la distorsión de las ideas originales). Sin embargo, el universalismo todavía no ha conseguido uniformizar las tradiciones jurídicas del mundo ${ }^{20}$, que reaccionan y desarrollan sus propios sistemas, incluso disociando la law in action del trend uniformizador de la globalización ${ }^{21}$. Este es un derecho sumergido e invisible, que decide el destino del «tercer y más amplio círculo concéntrico [...] compuesto por todos aquellos que ya están excluidos del sistema global» ${ }^{22}$.

De la perspectiva substancial, conlleva: enfatizar los derechos individuales, pero al mismo tiempo justificar (o al menos aceptar) limitaciones a los derechos, a nivel constitucional, legislativo, jurisprudencial, en nombre de la defensa de la democracia; en particular, preparar el terreno para favorecer la democracia protegida de manera funcional a la realización del proyecto del free trade market of ideas; patrocinar o avalar la sustitución de la mediación partidaria, sindical, asociativa, con otras formas de representación, ancladas a la atomización de los sujetos (uno vale uno).

A nivel procesal, una vez negado o circunscrito el papel de la política para la composición de los intereses y en el balance de los valores, la formulación, la defensa y la expansión del núcleo se vale por lo menos de tres modalidades principales: la sustracción del mismo a cualquier posiblidad de modificación, cualesquiera que sean las opciones de la sociedad y los valores que elija; el desarraigo de los mismos, desvinculados de procesos legitimadores, mediante la superioridad conferida al derecho de los tratados, considerado superior a las constituciones mismas; la confianza en el conocimiento de los jueces-demiurgos nacionales e internacionales de las decisiones sobre conflictos de prevalencia (en la práctica, qué es justo y qué no lo es).

\section{LA ELABORACIÓN DEL NÚCLEO DURO EN EL DERECHO EURO-ATLÁNTICO}

En el derecho euro-atlántico, la operación pasa por diversas modalidades sea en los formantes político y normativo o en el jurídico-doctrinal, a menudo alineados.

En los formantes político y normativo (constituciones, revisiones constitucionales, leyes), la realización de los objetivos uniformadores se traduce en la erosión de las fórmulas clásicas de la representación, con la distrución o reducción de la sociedad intermedia (partidos, sindicatos, hasta los Parlamentos), de donde se

20 Remito a mis escritos anteriores, esp. a «Constitucionalización del derecho y cultura constitucional», Revista de Derecho Político, n.104, 2019, p. 13 ss.

21 Cfr. Siems, M., Comparative Law, Cambridge U.P., Cambridge, 20 I4, p. 233 ss. La conservación del pluralismo de las tradiciones jurídicas es defendida por W. Menski, Comparative Law in a Global Context: The Legal Systems of Asia and Africa, 2. ${ }^{a}$ ed., Cambridge U.P., Cambridge, 2006.

22 Ortino, S., La struttura delle rivoluzioni economiche, cit., p. 406, se refiere a Hoogvelt, A., Globalization and the Postcolonial World: The New Political Economy of Development, Johns Hopkins U.P., Baltimore, 1997: la humanidad se divide en tres círculos concéntricos. Al tercero, más externo, se añaden uno interno (las élites que se benefician de la globalización) y uno intermedio (los trabajadores precarios). 
alimentaban el consenso y el control del consenso; la edificación de una sociedad segura, sólidamente anclada a la ciudadanía y el tendencial rechazo al extranjero; el control de las libertades sociales, subordinadas a la aceptación de una ponderación de los valores a favor de los económicos, encomendados a sujetos ajenos al circuito democrático (derecho transnacional y jueces); la restricción de los derechos políticos, condicionados a la aceptación del núcleo, la ya generalizada limitación de la libertad de partido (democracia protegida como regla), hasta la limitación de la esfera individual, con nuevas formas de control persuasivas, justificadas por la seguridad, reforzadas para garantizar las libertades individuales.

En el formante jurídico-doctrinal, encuentra un fuerte apoyo, entre otros, en el fuerte ataque a la política como categoría (y no sólo a sus desviaciones), en favor de actores no directamente legitimados (jueces y varias sedes extranacionales: el derecho convencional), y en el argumento apagógico que para defender el núcleo duro de la democracia hay que combatir quien no acepta tal núcleo (los derechos y la división de los poderes).

La doctrina constitucionalista ha proporcionado el marco para la radical transformación en curso. Partiendo de experiencias circunscritas, ya sean la Selva Negra o las praderas del Middle West, como en Häberle o Dworkin, ha asignado al núcleo de los derechos, llamados «fundamentales» porque así los denomina el Grundgesetz, o «constitucionales» porque son codificados en específicas constituciones occidentales, o «humanos», porque de tal manera son calificados en cartas universales o regionales, un rango superconstitucional y transnacional: sin límites en los pueblos, sin límites en los territorios, sin límites en los gobiernos, al igual que en la economía de la globalización. El parroquialismo de esta visión se expresa bien en la bibliografía de los libros de sus principales artífices y de sus seguidores, donde nunca se cita a nadie que no haya nacido y vivido en el barrio ${ }^{23}$.

Se trata prevalentemente de derechos individuales de matriz liberal y burguesa; el esfuerzo por ampliar la categoría a los derechos políticos, sociales y culturales es puramente nominalista, encontrando estos últimos un límite insuperable en la absolutización de la dignidad de la persona, que es algo que concierne (principalmente, si no sólo) a los individuos ${ }^{24}$. Lo demuestra, en los últimos años, la jurisprudencia de la Corte Interamericana, que siempre intenta reconducir también los derechos sociales, culturales y económicos en el cauce de la dignidad ${ }^{25}$.

23 El punto no es sólo mío. Por ej., Chakrabarty, D., La poscolonialidad y el artilugio de la historia: ¿quién habla en nombre de los pasados «indios»?, Centro de Estudios de Asia y África, El Colegio de México, 1999 dice de los académicos y académicas occidentales que «producen su obra en una relativa ignorancia de las historias no occidentales y esto no parece afectar la calidad de su trabajo. Éste es un gesto, sin embargo, al que "nosotros" no podemos corresponder. Ni siquiera podemos permitirnos una igualdad o simetría de ignorancia a este nivel sin correr el riesgo de parecer "anticuados" o "superados"».

24 Y sólo por reflejo, alguna vez, por los grupos: ver PICIOCCHI, C., La dignità come rappresentazione giuridica della condizione umana, Cedam, Padova, 2013.

25 Sobre la evolución de la jurisprudencia de la CIDH en esta dirección, RAGONE, S., «The Inter-American Court of Human Rights turned 40: achievements and challenges», Rev. gen. der. públ. comp., n. ${ }^{\circ}$ 25, 2019 , p. 1 ss. 


\section{Límites a los derechos individuales}

El énfasis puesto en los derechos individuales, por lo tanto, no excluye en modo algunos límites a su ejercicio, si son funcionales no sólo a las libertades de otros particulares, sino también al bien común. Pero no están justificados — como en el Estado liberal - por la exigencia del Estado de asegurar la paz interna y la externa, según la propuesta del gran Hobbes, sino por el mantenimento de la «democracia», es decir, el sistema que asegura el ejercicio de los derechos y la división de los poderes ${ }^{26}$. La razón parece ser evidente: la forma democrática es funcional al neoliberalismo ${ }^{27}$.

El ataque a los derechos se lleva a cabo en nombre de la seguridad invocada por los legisladores, y a menudo (aunque no siempre) por los jueces y la doctrina, sobre todo para avalar medidas restrictivas y rotundamente discriminatorias entre ciudadanos y estranjeros. La privacy — the right to be let alone- desvaneció en Occidente a favor del control cotidiano del Estado y de entitades públicas y privadas, realizando, no ya en el mundo del socialismo real, como imaginaba Orwell, sino en las liberal-democracias, la pesadilla del Gran Hermano. Sobre todo, se afirma la limitación de los derechos individuales, como el habeas corpus, el due process, etc. La limitación de los derechos individuales no es sólo un problema de derechos individuales, más bien de cultura y culturas, sociedad, economía, política, instituciones y control de las mismas.

\section{Derechos de asociación, políticos y de representación}

En el campo de los derechos de asociación y políticos, las nuevas constituciones (y a menudo la jurisprudencia), atentos según mandato doctrinal a la misión de proteger la democracia y los derechos, permiten la libre competición política sólo en el respeto de principios estrictos.

26 Hoвbes, T., Leviathan (1651), ed. e introducción de M. OAкEshotт, Blackwell, Oxford, 1955, Part II, ch. 17 «Of the Causes, Generation, and Definition of a Commonwealth»: «This is more than consent, or concord; it is a real unity of them all in one and the same person, made by covenant of every man with every man, in such manner as if every man should say to every man: I authorise and give up my right of governing myself to this man, or to this assembly of men, on this condition; that thou give up, thy right to him, and authorise all his actions in like manner. This done, the multitude so united in one person is called a Commonwealth; in Latin, Civitas. This is the generation of that great Leviathan, or rather, to speak more reverently, of that mortal god to which we owe, under the immortal God, our peace and defence». Sobre la primera ley natural de Hobbes (buscar la paz), el recurso a la guerra, la muerte del enemigo («the object is to every man his own good»; «every man has a right to every thing; even to one another's body»: Leviathan, cit., p. 99 y 85), v. las esplendidas páginas de SCARPELli, U.,Thomas Hobbes. Linguaggio e leggi naturali. Il tempo e la pena, Giuffrè, Milano, 1981, p. 41 ss.; sobre ellas me detengo en «El enemigo, la ecuación terrorista-estranjero y el ataque al Estado democrático de Derecho», Dir. pubbl. comp. eur., n. ${ }^{\circ}$ especial, 2019, p. 611 ss.

27 Cfr. Kurki, M., «Democracy and Conceptual Contestability: Reconsidering Conceptions of Democracy in Democracy Promotion», Int. st. rev., n. ${ }^{\circ} 12,2010$, p. 366. 
La orientación, inaugurada por la Grundgesetz y por lo demás avalada por la doctrina $^{28}$, es aquella que extiende la protección de la democracia a contenidos específicos: esto es, perseguir no sólo a las asociaciones políticas que amenazan indeterminadamente la ideología «democrática» tradicional (comunistas, fascistas) o formaciones que luchan por la secesión de una parte del territorio ${ }^{29}$, sino también a las que amenazan otros principios considerados básicos (que, en otras palabras, constituyen el llamado núcleo duro), debidamente enumerados. Según la Ley fundamental alemana, las asociaciones políticas no deben «dañar o eliminar el ordenamiento fundamental democrático y liberal», están prohibidas además las que no se encuentren «en conflicto con las leyes penales, o se dirijan contra el ordenamiento constitucional o contra el principio de tolerancia entre los pueblos» ${ }^{30}$. Se prohíbe a partidos y asociaciones políticas que amenazan el pluralismo político y los principios del Estado de derecho (Rumania), a la soberanía nacional, el régimen democrático, el pluralismo, los derechos fundamentales de la persona humana (Brasil); que propugnan la incitación al odio racial, nacional, étnico o religioso (Bulgaria, Macedonia); que amenazan los derechos y libertades de los otros individuos (Bulgaria). Georgia prohíbe a los partidos promover la propaganda de la guerra, la violencia, o provocar el odio nacional, regional o social ${ }^{31}$. En Costa Rica

28 Pero con posiciones distintas: v. en clave comparada, en español, Corcuera Atienza, J.; TajAdura Tejada, J.; Vírgala Foruria, E., La ilegalización de partidos políticos en las democracias occidentales, Dykinson, Madrid, 2008; en italiano CECCANTI, S., Le democrazie protette e semi-protette da eccezione a regola. Prima e dopo le Twin Towers, Giappichelli, Torino, 2004; Di Giovine, A. (ed.), Democrazie protette e protezione della democrazia, Giappichelli, Torino, 2005; Di Giovine, A., SiCARDi, S. (eds.), Democrazie imperfette, Giappichelli, Torino, 2005; en inglés, SAjó, E. (ed.), Militant Democracy, Eleven International Publ., Utrecht, 2004, y «The Self-Protecting Constitutional State», East Eur. const. rev., n. ${ }^{\circ} 12$ (2-3), 2003. Con una mirada particular sobre el problema específico de los ordenamientos que provienen de regímenes autoritarios, Di GREGORIO, A., Epurazioni e protezione della democrazia. Esperienze e modelli di "giustizia post-autoritaria», Angeli, Milano, 2012. En general, Català I BAs, A., La (in)tolerancia en el estado de derecho, Rgd, Valencia, 2002.

29 Así lo establecen tanto las constituciones o la legislación que limitan la libertad política colectiva a las formaciones que respeten el «orden constitucional» o bienes similares (Alemania, Costa Rica, Estonia, Lituania), y más aún las que utilizan fórmulas codificadas específicamente, por ejemplo: Croacia («la independencia, la unidad y la integridad territorial»), Rumania («la soberanía, la integridad o la independencia»), Bulgaria («la soberanía, la integridad territorial del país y la unidad de la nación»), Georgia («la independencia, la integridad territorial del país ...»), Brasil («soberanía nacional»), Turquía («la integridad e indivisibilidad del territorio y la nación»), India («soberanía e integridad»), etc.

30 Art. 92 GG alemán. No existe mucha diferencia en esta disciplina, entre la constitución alemana y Europa del Este. Por ej., véanse las constituciones de Rumania, Bulgaria, Georgia (artt. 40 const. Rumania, 11 e 44 const. Bulgaria, 26 const. Georgia). Un análisis más detallado en Pegoraro, L., Rinella, A., Derecho constitucional comparado, II, Sistemas constitucionales, 2 vols, Astrea-Giappichelli, Buenos Aires-Torino, 2018, vol. B, p. 439 ss., y en Pegoraro, L., «Entre sociedad y Estado: los partidos políticos. Un acercamiento desde la perspectiva del Derecho constitucional comparado», Rev. gen. der. públ. comp., n. ${ }^{\circ} 23,2018, \S 7$. V. finalmente Locchi, M.C., La disciplina giuridica dei partiti a orientamento religioso, Giappichelli, Torino, 2018.

31 En Turquía, la constitución prevé varios límites a la actividad de los partidos: «la independencia del Estado, su integridad y no divisibilidad territorial y nacional, los derechos humanos, los principios de igualdad y del Estado de derecho, la soberanía de la nación, el principio republicano democrático y secular [...]». También la constitución de Marruecos (art. 7.1) enumera una serie de límites: «Los partidos no pueden fundarse sobre una base religiosa, lingüística, étnica o racial, o, de un modo general, sobre cualquier otra base discriminatoria o contraria a los derechos humanos». Por otra parte, «No pueden tener como objetivo atentar 
(art. 98, los partidos deben respetar en sus programas «el orden constitucional»y asegurar la organización interna y el «funcionamiento democrático» ${ }^{32}$.

La tendencia a la casi incondicional protección de la democracia, id est de permitir la competición política sólo a quienes estén de acuerdo con el núcleo duro del constitucionalismo, encuentra amplio apoyo en las corrientes doctrinales que, en nombre de la democracia (no del «método democrático», nótese, es decir el rechazo de la violencia, que es otra cosa, como lo señalaban claramente los constituyentes italianos), parece expresar en esta inspiración represiva un buen motivo para justificar intervenciones internas pero sobre todo externas, para que las llamadas «transiciones democráticas» puedan tener un buen fin ${ }^{33}$. Obviamente, la doctrina mainstream está de acuerdo en censurar intentos análogos realizados en defensa de «otros» órdenes constituídos, como por ej. la defensa del «núcleo» del socialismo y del papel del partido comunista cubano, a pesar de que en la nueva constitución había participado y debatido una amplísima parte de la población, que la ha aprobado ${ }^{34}$.

contra la religión musulmana, al régimen monárquico, los principios constitucionales, los fundamentos democráticos o a la unidad nacional y la integridad del territorio del Reino». Por último, para evitar erradas interpretaciones, concluye que: «La organización y funcionamiento de los partidos políticos deben ser conformes con los principios democráticos». Un caso aparte — en este contexto- está representado por la protección en contra de la confesionalidad, como en México, donde el art. 130, letra e), establece que «Queda estrictamente prohibida la formación de toda clase de agrupaciones políticas cuyo título tenga alguna palabra o indicación cualquiera que la relacione con alguna confesión religiosa ...».

32 Art. 98 const. En el caso de la constitucionalización, es necesario evaluar cuidadosamente las fórmulas utilizadas: lo que a primera vista puede parecer una norma abierta a los partidos antisistema, a menudo, se revela como una autorización para que el poder legislativo (es decir, una mayoría simple) pueda hacer aquello que quiera. Esto sucede cuando la constitución hace un reenvío a la ley para identificar asociaciones, partidos o actividades prohibidas, permitiendo de hecho cualquier limitación de contenido. Es el caso de Estonia, República Checa, Lituania. En todos estos ordenamientos, de hecho, la constitución encomienda a las leyes — - según el esquema de las constituciones ochocentistas - establecer los límites.

33 Sobre la democracia protegida o militante: Loewenstein, K., «Militant Democracy and Fundamental Rights», Am. pol. sc. rev., n. ${ }^{\circ} 31$ (3-4), 1937, p. 417 ss.; Contrôle législatif de l'extrémisme politique dans les démocraties européennes, Lgdj, Paris, 1939; Über das Verhältnis von politischen Ideologien und politischen Institutionen, Beiträge zur Staatssoziologie, Mohr-Siebeck, Tübingen, 1961, p. 245 ss. Sobre las clasificaciones PEGORARO, L., «Para una clasificación «ductil» de «democracia militante», Est. const., n. ${ }^{\circ}$ 6, 2012, p. 119 ss., en Cruz Barney, O., Da Cunha Lopez, T., Pegoraro, L. (eds.), Ensayos sobre Derecho Comparado y Constitución, Aaa, Morelia, 2013, p. 7 ss., Cienfuegos Salgado, D., Rodríguez Lozano, L.G. (eds.), Temas selectos de Derecho Público contemporáneo, Uanl-El Colegio de Guerrero-Laguna, México, 2012, p. 249 ss.

34 Durante el proceso de reforma se han celebrado más de 1000.000 reuniones para el debate sobre el proyecto, con la participación de cerca de 9 millones de personas. Las opiniones favorables al proceso de consulta representarían el $62 \%$ del total y las críticas el 3\%. Todas las intervenciones de la población se agruparon en 9.595 "propuestas tipo», de las cuales 4.809 (el 50,1\%) fueron aceptadas, mientras que las restantes fueron consideradas inapropiadas por no ser pertinentes a la materia constitucional. Las opiniones de los cubanos residentes en el exterior se agruparon en 978 «propuestas tipo», de las cuales 391 fueron aceptadas, es decir, el 40\%. En total, la comisión redactora realizó 760 modificaciones al borrador licenciado por la Asamblea Nacional el 22 de julio, modificaciones que van desde una palabra o frase hasta la inserción de un párrafo o un artículo completo. El texto definitivo fue aprobado el 22 de diciembre de 2018, con votación unánime de los diputados presentes, y confirmado por referéndum el 24 de febrero de 2019. En total fueron modificados 134 artículos de la propuesta inicial, es decir, casi el 60\%, tres fueron derogados y 87 no sufrieron modificaciones. (Aspromonte, V.A., Cuba: verso una nuova costituzione, tesis Bologna, SPS, a.a. 2017-2018). Sobre la nueva constitución de Cuba v. la sección monográfica de Dpce on-line, n. ${ }^{\circ}$ 1, 2020. 


\section{Derechos de status}

El extranjero migrante asume humanidad sólo en la medida en que se viole su derecho individual, nunca o casi nunca como categoría, clase representativa de alteridad, ni se discute la clara contradición entre «derechos humanos» y «ciudadanía» para el disfrute de los derechos distintos de los personalísimos. Es raro, por ejemplo, leer interpretaciones «jurídicas» y «constitucionalistas» de los problemas migratorios declinados en términos disintos a los dados por la violación de los derechos ${ }^{35}$.

Pocos conocen la política de Theresa May del llamado hostile environment, señalada por M. Nicolini ${ }^{36}$ : «In our social imaginaries, this process of displacement and spatial marginalisation triggers a "really hostile environment for [allegedly] illegal immigrants" 37 , i.e., a by-product of "heightened border measures that restrict migration, measures that play well with anxious electorates and hawkish politicians"; in so doing, states disavow "the West's complicity in the wider social, political and economic conditions that contribute to the migrations the West seeks to secure" 38 . But this also accounts for another application of strategic formalism: the securitisation of climate-induced migration. Whilst praising the economic benefits of global mobility and the protection of migrants' rights, "politicians work together across borders to make it more difficult for people to move, while capital is allowed to flow freely" ${ }^{39}$.

La idea «no taxation without representation», verdadero pilar de nuestro constitucionalismo, es sacrificada en el altar de la ciudadanía ${ }^{40}$. La marginación de los «no ciudadanos» de las decisiones políticas, contra la que se produjeron las «revoluciones» inglesa — desde el siglo XIII—, y americana, es sancionada a nivel

35 Entre las excepciones, Amirante, D., Pascali, M., Alien. Immigrazione clandestina e diritti umani, Ed. scientifica, Napoli, 2015, p. 10, destacan que «El debate político, la 'vulgata' multimedial y a veces también la investigación científica ignoran o subestiman las relaciones dialécticas fundamentales que impiden apreciar en su realidad, no solo ideológica, la presencia de inmigrantes en el territorio nacional». Cfr. también el análisis histórico-jurídico de Colomer Viadel, A., Inmigrantes y emigrantes. El desafío del mestizaje, Ciudad Nueva, Buenos Aires, 2016, y en clave metodológica BAgni, S., Lo Stato interculturale: primi tentativi di costruzione prescrittiva della categoria, en Bagni, S., Figueroa Mejía, G. A., Pavani, G. (eds.), La ciencia del derecho constitucional comparado. Estudios en homenaje a Lucio Pegoraro, 3 vols, Tirant, México, 2017, II, p. 111 ss.

36 Nicolini, M., «Law and the Humanities in a Time of Climate Change», The Cardozo Electr. Law Bull., n. ${ }^{\circ} 26$ (1), 2020, p. 1 ss.

37 Véase Kirkup, J., Winnett, R., «Theresa May Interview: 'We're Going to Give Illegal Migrants a Really Hostile Reception», The Telegraph, 25.05.2012.

38 Véase Baldwin, A., «Pluralising Climate Change and Migration: An Argument in Favour of Open Futures», en Geography Compass, n. ${ }^{\circ}$ 8, 2014, p. 521 ss, y White, G., Climate Change and Migration: Security and Borders in a Warming World, Oxford U.P., Oxford, 2011.

39 Goodfellow, M., Hostile Environment: How Immigrants Became Scapegoats, Verso, London, 2019, p. 39 .

40 Núñez Torres, M.G., Cavazos Guajardo Solís, A., «El principio de no taxation without representation, la migración y su impacto en los ordenamientos jurídicos latinoamericanos», Rev. gen. der. públ. comp., n. $.^{\circ} 20,2017$. 
académico por el olvido de las raíces liberales de la igualdad, que en el pasado, pero ya no, justificaron la admisión de nuevas clases al ejercicio del poder.

Los estándares de democracia elaborados por entidades supranacionales o internacionales (en particular aquellos dirigidos a finalidades prácticas, como la admisión o no de un Estado a la Unión Europea) abrazan visiones universalistas, como el Document of the Copenhagen Meeting of the Conference on the Human Dimension of the CSCE $E^{41}$ : utilizado para evaluar la ampliación de la Unión Europea a nuevos Estados, minucioso e incluso pedante en algunos aspectos (la facilitación del programa Erasmus es un estandard), sobre el tratamiento de los extranjeros afirma en el punto 22.1 que los Estados «agree that the protection and promotion of the rights of migrant workers are the concern of all participating States and that as such they should be addressed within the CSCE process». Otras cláusulas se refieren a convenios multilaterales o a compromisos genéricos. Autorizan disciplinas discriminantes entre ciudadanos y extranjeros, incluso para el disfrute de los derechos civiles, y no se menciona a los derechos políticos, y en particular al control, a través del voto u otros métodos, de los ingresos generados por el trabajo de los extranjeros ${ }^{42}$.

\section{LA DEFENSA DEL NÚCLEO}

En el plano procesal, la defensa del núcleo duro de los derechos (aunque con los límites antes señalados) tiene como primera repercusión la aceptación cada vez más generalizada de límites intensos a la revisión constitucional. Con pocas excepciones (EE.UU., Francia), los Tribunales Constitucionales, apoyados por una gran parte de la doctrina académica, independientemente de las supermayorías previstas por cada constitución para aprobar la reforma (y también de la frecuente participación del pueblo «soberano»), se proponen como únicos intérpretes del bien del pueblo y prohiben reformar lo que no les gusta, incluso en ausencia de límites expresos en el texto originario ${ }^{43}$.

41 Para un análisis con otros ejemplos, CASSESE, S., «Global standards for national democracies?», Riv. trim. dir. pubbl., n. ${ }^{\circ}$ 3, 2011, 701 ss.

42 Véase los puntos por los que los Estados (22.2): «reaffirm their commitment to implement fully in their domestic legislation the rights of migrant workers provided for in international agreements to which they are parties»; (22.3): «consider that, in future international instruments concerning the rights of migrant workers, they should take into account the fact that this issue is of importance for all of them»; (22.4): «express their readiness to examine, at future CSCE meetings, the relevant aspects of the further promotion of the rights of migrant workers and their families». Sobre este aspecto infra, § 8.1. Cfr. Pegoraro, L., «Costituzioni e democrazia: definizioni e classificazioni nel costituzionalismo contemporaneo», Rass. parl., abril/junio 2014 .

$43 \mathrm{Si}$ los jueces de las leyes están habilitados a criticar en la forma y/o en el mismo contenido la revisión constitucional, el control de constitucionalidad, desde el control sobre los abusos de la mayoría, en nombre de la supremacía constitucional, se convierte en el control del poder constituyente — encarnado por los Tribunales_- sobre el poder constituido, en todas sus manifestaciones. Sobre este aspecto RAGONE, S., El control judicial 
Una consecuencia de la teoría de que existen «principios supremos de la constitución», en cuanto tales inmodificables incluso para el poder de revisión constitucional, y de los que son los atentos guardianes, coloca a los Tribunales Constitucionales no sólo sobre el poder legislativo, sino verdaderamente al lado del constituyente. Esto evoca el tema de la legitimación de los Tribunales Constitucionales (y del control mismo de constitucionalidad) ${ }^{44}$. Lo cual ha sido afrontado de manera y con conclusiones diversas ${ }^{45}$ : sintéticamente, o para subrayar la falta de compatibilidad con el principio democrático, o por afirmar su coesencialidad, con la finalidad de no identificar la democracia con el mero principio mayoritario $^{46}$. La primera conclusión (incompatibilidad) se inserta en una teoría de la constitución que —incluso cuando admite el control — encomienda al pueblo la supremacía, si con los procedimientos y las mayorías prescritas decide derogar o cambiar la misma constitución. La segunda (coesencialidad) se alza sobre la idea de la constitución como tabla de valores «metademocráticos», de los cuales los tribunales son los únicos intérpretes, siendo el legislador un mero aplicador del texto constitucional. Esta es la idea predominante hoy ${ }^{47}$.

de la reforma constitucional. Aspectos teóricos y comparativos, Porrúa, México, 2012; «El control material de las reformas constitucionales en perspectiva comparada», Teoría y Realidad Constituconal, n. ${ }^{\circ}$ 31, 2013, p. 391 ss.; sobre la importancia del control (siempre más frecuente) sobre las revisiones constitucionales cfr. GözLER, K., Judicial Review of Constitutional Amendments: A Comparative Study, Ekin, Bursa (Turqía), 2008; BAGNi, S., Riforme costituzionali e super-maggioranze parlamentari: per un aggravamento variabile del procedimento di revisione, en BUTTURINI, D., Nicolini, M. (eds.), Giurisdizione costituzionale e potere democraticamente legittimato, 2 vols, I, I soggetti, gli strumenti e i meccanismi del dialogo, Bup, Bologna, 2017, y en Álvarez Conde, E. (ed.), Álvarez Torres, M. (coord.), Reflexiones y propuestas sobre la reforma de la Constitución española, Comares, Granada, 2017.

44 Tusseau, G., «Deux dogmes du constitutionnalisme», en AA.VV., Penser le droit à partir de l'individu. Mélanges en l'honneur d'Élisabeth Zoller, Dalloz, Paris, 2018, p. 835 ss.

45 Ely, J.H., Democracy and Distrust: A Theory of Judicial Review, Harvard U.P., Cambridge, 1980; Dworkin, R., A Matter of Principle, Harvard U.P., Harvard, 1985; BICKEL, A., The Least Dangerous Branch: The Supreme Court at the Bar of Politics, 2. ${ }^{a}$ ed., Yale U.P., New Haven-London, 1986; Ackerman, B., We the People, Harvard U.P., Cambridge, 1998; Bork, R.H., Coercing Virtue: The Worldwide Rule of Judges, Am. Enterprise Inst., Washington D.C., 2003; Tremblay, L.B., «The Legitimacy of Judicial Review», I.CON, n. ${ }^{\circ} 3$ (4), 2005, p. 617 ss.; GroppI, T., «La legittimazione della giustizia costituzionale», Percorsi cost., n. ${ }^{\circ} 2-3,2010$.

46 Rostow, E.V., «The Democratic Character of Judicial Review», Harvard L.R., n. ${ }^{\circ}$ 66, 1952, p. 193 ss.; Favoreu, L., «Actualité et légitimité du contrôle juridictionnel des lois en Europe occidentale», Rev. dr. publ. sc. pol., n. ${ }^{\circ}$ 5, 1984, p. 1147 ss; Troper, M., «Justice constitutionnelle et démocratie», Rev. fr. dr. const., n. ${ }^{\circ} 1,1990$, p. 31 ss.; AA.VV., Legitimidade e Legitimação da Justiça Constitucional, cit.

47 La primera tesis conlleva el riesgo de que una mayoría, tal vez casual, pueda subvertir del fundamento un texto constitucional fruto de compromisos y conciliaciones; es decir las reglas del juego. La segunda tesis presupone la existencia de valores que de todos modos, y por todas partes, son siempre compartidos por todos o casi todos (se habla a menudo de «dignidad») y que ninguno podría extinguir o actualizar: ni siquiera el pueblo, pero los tribunales si. Cualquiera que sea la solución seleccionada, permanece el hecho de que quienes dan un sentido a la constitución son siempre, en último término, los intérpretes. Y, a excepción del poder de revisión — cuando los propios Tribunales no lo limitan — para interpretar la constitución son las mismas Cortes. Un análisis crítico de las teorías expuestas en Díaz Revorio, F.J., La "Constitución Abierta» y su Interpretación, Palestra, Lima, 2004; Valores superiores e interpretación constitucional, Trib. Estatal Electoral, Chihuahua, 2009; Id, Interpretación de la Constitución y justicia constitucional, Porrúa, México, 2009; y en PeGoraro, L., Sistemi di giustizia costituzionale, Giappichelli, Torino, 2019, cap. II, § 8; Id «Politico» e «giurisdizionale» a cento anni dal Verfassungsgerichtshof, Dir. pubbl. comp. eur., n. ${ }^{\circ}$ 4, 2020. 
Las doctrinas neoconstitucionalistas, que en las versiones más radicales entregan a los Tribunales Constitucionales la ponderación de valores, incluso sin tener en cuenta los límites, acaban con legitimar un activismo incesante, desequilibrando sus funciones de freno y corrección. Entre las opciones de los representantes del pueblo, también en sede de revisión, y aquellas de los jueces de las leyes (o de las revisiones), deberían siempre prevalecer estos últimos, los portadores de los valores universales (de los cuales tales doctrinas se hacen a su vez intérpretes, autoatribuyéndose el poder de decidir lo que es válido, útil y esencial en todas partes y para siempre).

La crisis democrática se percibe entonces en la atribución a los tratados internacionales y los convenios sobre derechos (aprobados casi siempre por los Gobiernos o la mayoría simple de los Parlamentos) de un rango superior a aquel de las propias constituciones elaboradas por el poder constituyente o de reformas constitucionales decididas por amplias mayorías o por el pueblo ${ }^{48}$. La «higher law» por lo tanto no es la ley aprobada por «we the people», sino la decidida por Gobiernos y Parlamentos en desprecio de lo que afirmó Hamilton en el ensayo n. ${ }^{\circ} 78$ del Federalist ${ }^{49}$.

Incluso donde la superioridad de los tratados está fijada en la constitución, y no solamente fue decidida en la jurisprudencia, esta se convierte en flexible, atribuyéndose (casi siempre) a las mayorías simples (o a los Gobiernos), a través de los tratados, el poder de individualizar las reglas supremas. E incluso cuando la superioridad de los tratados se establece por la constitución, se convierte en flexible, siendo los casos siempre encomendados a las mayorías simples (o los Gobiernos), mediante los tratados, individuar las reglas supremas ${ }^{50}$.

\section{EL LADO OBSCURO DE LA FUERZA: LAS ASPIRACIONES IMPERIALES DEL CONSTITUCIONALISMO CONTEMPORÁNEO (Y DE LA JURISPRUDENCIA CONSTITUCIONAL E INTERNACIONAL)}

Según muchos constitucionalistas — casi todos los estadounidenses, y la mayoría de europeos y latinoamericanos- el mundo sólo es un terreno fértil donde las ideas occidentales pueden echar raíces (el jurista como «político del

48 Sobre el derecho convencional, vid. bibliografia en Pegoraro, L., Rinella, A., Constituciones y fuentes del derecho, cit., cap. II, $\$ 3$.

49 «Si hubiera una antinomia irremediable entre la ley constitucional y la ley ordinaria, se deberá, naturalmente, dar preferencia a aquella que estamos ligados por obligaciones mayores o, en otros términos, se deberá preferir la constitución, a la voluntad de los representantes del pueblo la voluntad del pueblo mismo».

50 El vulnus es menos evidente donde, como en la constitución estadounidense (art. II, secc. II, § 2), se prevé que la aprobación de los tratados exige el favor de 2/3 de los senadores, siendo así al menos en parte confirmada la naturaleza «contramayoritaria» del texto. En Brasil los únicos tratados sobre los derechos humanos son aprovados a 3/5 de las dos ramas del Congreso (art. 5, § 3 const.); en Argentina las cámaras votan muchos tratados a mayoría absoluta (artt. 24 e 75 const.), en México el Senado aprueba con mayoría simple (art. 76 const.). 
derecho» y observador interno de la norma) o, desde la perspectiva gnoseológica, donde viajar para contar cosas domésticas, sin ningún conocimiento de ello, ni propensión al aprendizaje y la comparación ${ }^{51}$.

Para conocer —antes de escribir o enseñar- es necesario renunciar a decidir estar del lado de la Verdad. Las doctrinas constitucionalistas a menudo no empujan en esta dirección. Presuponen una verdad, que utilizan como tertium comparationis y parámetro de evaluación, invocando muchas veces la pureza del método jurídico y la incontaminación de su propia ciencia, sin plantear el problema de lo que es jurídico en culturas que proponen diferentes significados de «derecho». Crean vallas: entre el bien y el mal, entre la civilización y los bárbaros, entre el sustrato cultural de las tradiciones y de las creencias y «el derecho», entre el derecho y las otras ciencias (occidentales), entre el derecho de los particulares y el derecho de las constituciones. El derecho comparado no renuncia a ser «derecho»; tampoco renuncia, en caso necesario, a la tradicional distinción entre lo público/ constitucional y lo privado. Sin embargo, reivindica con fuerza que no hay conocimiento del derecho constitucional sin conocimiento de las estructuras que regulan las relaciones entre las personas y entre ellas y las comunidades, y viceversa, que el estudio de estas últimas no puede desconocer la influencia que las «costituciones» de las sociedades tienen en las relaciones entre los individuos. Bien lo sabe quien conoce al menos un poco la India, China, o África, o América Latina por haberlos mirado direcatamente a los ojos y al corazón, captando su espíritu y perculiaridades y resignándose — como escribe Cacucci- «a una capitulación incondicional: la renuncia a sus propios patrones y hábitos, liberándose de la inconfesada certeza de que la realidad es única y unidimensional, y que todo puede ser interpretado con un sólo modo de ver. El ingrediente más nefasto de la cultura occidental creo que es precisamente nuestra instintiva costumbre de analizar y juzgar, filtrando los comportamientos a través de una red de convenciones que nos hacemos ilusiones sean absolutas y obvias» ${ }^{52}$.

Cuando el objeto de análisis es el mundo en su globalidad, o partes del mundo que no aceptan, o aceptan sólo en parte, concepciones occidentales de «derecho», los comparatistas son llamados al esfuerzo hercúleo de apoderarse de conceptos que son ajenos a ellos (o al menos para reconocerlos, para «percibirlos»), como los de «amae» (armonía) en el derecho japonés, «bexie» en el derecho chino (de nuevo, armonía), «dharma» (deber) en el derecho hindú, «ubuntu» o «fanaby maba-olona» (principio de existencia) en el derecho africano, «sumak kawsay» (buen vivir)» en el idioma kichwa, pero también otras expresiones ya mencionadas en el \&2: «deber», «moral», «religión», «naturaleza», «familia», «tribu», «perdón», «ocio», «tradición», «corrección», «deferencia», «felicidad», etc.,

51 Una «filosofía» que el Frankenstein de M. Shelley resume así: «How dangerous is the acquirement of knowledge and how much happier that man is who believes his native town to be the world, than he who aspires to be greater than his nature will allow».

52 Cacucci, P., La polvere del Messico, $14 .^{\mathrm{a}}$ ed., Feltrinelli, Milano, 2004. 
que no sólo condicionan pre-jurídicamente, sino vertebran el modo de entender lo que nosotros llamamos «derecho» ${ }^{53}$.

Doctrina y jurisprudencia, unidas en un abrazo «de Laocoonte», a menudo van en distinta dirección.

Los que abogan por un un positivismo monista edificado sobre el estatalismo presentan graves limitaciones de comprensión y representación de los derechos efectivamente vigentes y vinculantes. Son idóneos para explicar el derecho donde hay alineación entre cultura, cultura jurídica y normas "positivas» (en el sentido de «puestas» por el Estado), pero podríamos decir que, paradójicamente, fuera de los sistemas occidentales es precisamente el derecho positivo estatal el que a veces representa la desviación, cuando esporádicamente intenta prevalecer sobre el derecho general efectivamente eficaz, que ignora las prescripciones presuntamente «válidas» impuestas por cada Estado a la comunidad. Ésta, si incluso no ignora la existencia, sin embargo se siente vinculada a otros sistemas de reglas ${ }^{54}$.

Pero es sobre todo el planteamiento neoconstitucionalista, alimentado por estudiosos de diferentes países ${ }^{55}$, y recibido con entusiasmo por muchos Tribunales, el que legitima el «no derecho» de la globalización, proporcionando el soporte teórico para un sistema con pretensiones de universalidad basado en la uniformación totalizante y la aniquilación de las diversas culturas, en cuyo nombre se justifican operaciones de conquista no sólo jurídica (la «civilización de los bárbaros»), sino también política y económica ${ }^{56}$. Tales teorías se demuestran funcionales en

53 Cfr. por ej. Rosillo Martínez, A., «Fundamentar derechos humanos para desencriptar la Constitución», Rev. est. jur. UNESP, n. ${ }^{\circ} 29,2015$, p. 1 ss.; ID., Repensar derechos bumanos desde la liberación y la descolonialidad, en Dir. E práxis, n. ${ }^{\circ} 13,2016$, p. 721 ss.

54 Cfr. Somma, A., Introduzione al diritto comparato, cit., passim.

55 ... y muy evocado en América Latina, para contrarrestar el modelo de political law que caracteriza todavía el continente. Cfr. Sieder, R., Schjolden, L., Angell, A. (eds.), The Judicialization of Politics in Latin America, Palgrave Macmillan, New York, 2005. Sobre el neoconstitucionalismo v. entre tantos CARBONell, M. (ed.), Neoconstitucionalismo(s), 4. . ed., Unam-Trotta, Madrid, 2009; Dworkin, R., Taking Rights Seriously, Harvard U.P., Cambridge, 1977; en clave crítica, GuAstini, R., «A proposito di neo-costituzionalismo«, Teoria pol., nuova serie, n. ${ }^{\circ}$ 1, 2011, 147 ss., y — con corte diferente- RePoso, A., Dal costituzionalismo al neocostituzionalismo, en Bagni, S., Figueroa Mejía, G.A., Pavani G. (eds.), La ciencia del derecho constitucional comparado, cit., I, p. 1251 ss.; cfr. también SASTre ARIZA, S., Ciencia jurídica positivista y neoconstitucionalismo, McGraw Hill, Madrid, 1999.

56 Se ha dicho (BAGNI, S., «Comparative law and... love: contro la globalizzazione del diritto, per la globalizzazione del giurista», Ann. dir. comp. st. leg. 2017, p. 50 s.) que los conceptos de transnational law, global law, soft law «representan "el Mal" al que el comparatista debe oponerse, precisamente en la fase de su elaboración, que en el momento de su aplicación a casos concretos, ignoran lo que deberían presuponer, es decir, las vidas de las personas y de las comunidades destinatarias de esas normas, y prescindiendo de los contextos históricos, económicos, culturales y sociales, en los que viven, obedeciendo en cmabio a los intereses superiores del paradigma del desarrollo, convertido en humano [...] por el adjetivo "sostenibile"». Un ejemplo de esta presión globalizadora es Vietnam, que desde el Doi Moi (renovación) de 1986, también mediante las constituciones de 1992 y de 2013, ha tratado de conjugar el centralismo democrático socialista y la tradición confuciana con elementos heterodirectos como, precisamente, la separación de poderes, el liberalismo económico y los derechos humanos —en contraposición a los «citizens' basic rights»—, impuestos por la comunidad internacional. Al respecto ver GiaO V.C., Tran, K., «Constitutional Debate and Development on Human Rights in Vietnam», Asian journ. comp. law, n. ${ }^{\circ} 11$ (2), 2016, p. 235 ss.; Pham, D.N., «From Marx to Market: The 
el interior (donde justifican el vaciamiento de poder de los cuerpos representativos y del mismo poder de reforma constitucional; en definitiva, de la política y del principio de soberanía popular), como en el exterior; se lleva a cabo con varios instrumentos, pero se justifica casi siempre con el fin de preservar los derechos fundamentales/humanos y ser instrumentos de la misma democracia, cuyo sentido sin embargo se va perdiendo cada vez más.

El asalto que incluso la constitución sufre hoy por parte de fuentes supranacionales o transnacionales ( $\mathrm{y}$ de las corrientes neoconstitucionalistas), a favor de los «núcleos duros» de las constituciones individualizados con técnicas casuísticas por profesores y Tribunales Constitucionales con total arbitrariedad, aprovechando el léxico a menudo vago o ambigüo de los textos ${ }^{57}$ sirve para encubrir o justificar la destrucción de la jerarquía de las fuentes y el declive de su formalismo (especialmente por el soft law $w^{58}$ ), la limitación de los derechos, el control social, la concentración del poder en los ejecutivos, acentuada por la crisis económica y sanitaria, y sobre todo en entitades sin legitimidad democrática. Sirve también para alimentar formas alternativas de decisión, cuyo presupuesto es la simplificación y la atomización de los procesos formativos de las decisiones y de las propias decisiones.

En el frente externo al derecho occidental, la misma idea de los derechos humanos es invocada como criterio de evaluación política (pero con una dimensión pseudo-jurídica) de sistemas «diferentes», como factor de equilibrio con otros valores, como causa legítima de las intervenciones, como un elemento de colonización económica y cultural. El universalismo de los derechos sirve de apoyo indispensable al universalismo de los mercados - la globalización. Puede servir para justificar los ataques a los derechos sociales, en nombre del mercado, cuando en los juicios de ponderación realizados por los Tribunales nacionales e internacionales se acentúan los intereses de dominio respecto de los de autonomía, de libertad y de crédito $^{59}$. Arrastra consigo la consiguiente cancelación del pluralismo cultural.

Come recuerda $\mathrm{R}$. Toniatti, «the UNESCO Constitution explains: In our increasingly diverse societies, it is essential to ensure harmonious interaction among people and groups with plural, varied and dynamic cultural identities as

Debates on the Economic System in Vietnam's Revised Constitution», Asian Journal of Comparative Law, n. ${ }^{\circ} 11$ (2), 2016, p. 263 ss. y espec. p. 269. Sobre el desarrollo constitucional vietnamita: SideL, M., The Constitution of Vietnam: A Contextual Analysis, Hart, London, 2009.

57 Tanto en su actividad de delimitación de competencias de poderes y entitades, como en la reconstrucción de las ponderaciones de principios, valores, derechos hechas por el poder constituyente y el legislativo: L. Pegoraro, A. Rinella, Sistemas constitucionales, cit., vol. B, 379 ss.

58 Varios perfiles del soft law son analizados por Somma, A. (ed.), Soft law e hard law nelle società postmoderne, Giappichelli, Torino, 2009, y por MostacCI, E., La soft law nel sistema delle fonti: uno studio comparato, Cedam, Padova, 2008.

59 La referencia a la clasificación de Burlamaqui se encuentra en SCARPELLI, U., Diritti positivi, diritti umani: un'analisi semiotica, en CAPrioli, S., Treggiari, F. (coords.), Diritti umani e civiltâ giuridica, Pliniana, Perugia, 1992, p. 43. 
well as their willingness to live together. Policies for the inclusion and participation of all citizens are guarantees of social cohesion, the vitality of civil society and peace. Thus defined, cultural pluralism gives policy expression to the reality of cultural diversity. Indissociable from a democratic framework, cultural pluralism is conducive to cultural exchange and to the flourishing of creative capacities that sustain public life» ${ }^{60}$.

La Declaración universal sobre la diversidad cultural de la UNESCO manifesta su profunda lejanía del pluralismo (su hostilidad, me atrevo a decir) sobre todo allí donde sostiene que «cultural rights are an integral part of human rights, which are universal, indivisible and interdependent», definiendo la defensa de la diversidad cultural «an ethical imperative, inseparable from respect for human dignity», que «implies a commitment to human rights and fundamental freedoms, in particular the rights of persons belonging to minorities and those of indigenous peoples. No one may invoke cultural diversity to infringe upon human rights guaranteed by international law, nor to limit their scope».

Donde, por tanto, la «sagrada religión» que en Carlos V podía limitar los buenos usos y las tradiciones indígenas merecedoras de protección está representada por los límites ineliminables puestos por el democratic framework, la reconducción de los derechos culturales al cauce de los derechos humanos y la defensa irrenunciable de la dignidad, obviamente declinada según los canones occidentales. Se puede ir a misa vestido de indígena, pero se debe ir a misa.

S. Bagni escribe: «este enfoque, que presupone una forma de predominio de la cultura occidental sobre las "otras", se desdeña en los documentos internacionales adoptados en defensa de los derechos indígenas, sobre todo a través de la subordinación del derecho indígena al límite de conformidad con los derechos humanos, como en la Declaración de las Naciones Unidas sobre los Derechos de los Pueblos Indígenas del 2007 (art. 46) o en la Convención número 169 de la O.I.T. sobre los Pueblos Indígenas y Tribunales de 1989 (art. 35). (...) El reconocimiento de un status de los pueblos indígenas que incluya el derecho a aplicar a los miembros del grupo su propio sistema jurídico, tanto sustantivo como procesal, incluidas las instituciones de gobierno y jurisdiccionales propias de la cultura tradicional, puede de hecho ser anulado por cláusulas de subordinación al sistema de los "derechos humanos" de la tradición occidental» ${ }^{61}$.

Hay que preguntarse, en conclusión, qué tiene que ver el respeto de las culturas con los derechos humanos, si no es para vaciar de todo contenido semántico (e histórico) estos últimos. Poniendo todo dentro del significante, para reconducir todo a nuestras tradiciones, el resultado será precisamente el de negar las otras.

60 Toniatti, R., «Comparing Constitutions in the Global Era: Opportunities, Purposes, Challenges», Kansas L.R., n. ${ }^{\circ}$ 67, 2019, p. 707.

61 Dal Welfare State al Caring State?, cit., p. 25. 


\section{HACIA LA BÚSQUEDA DE UN DENOMINADOR COMÚN Y LA FORMULACIÓN DE UN NÚCLEO CONDIVISO Y NO IMPUESTO}

El instrumento cultural que acompaña el sueño imperial de la globalización económica es la elaboración de un núcleo de valores válidos para todos, que sirva de parámetro no sólo en las elecciones políticas y en la jurisprudencia de los varios ordenamientos que lo aceptan porque está arraigado en la historia, en la sociedad y en el derecho, sino también para los mundos externos ( $2 / 3$ del total), donde los formantes están rotundamente divididos. El mero reconocimiento de la diversidad es extremadamente parcial y limitado ${ }^{62}$.

Lo que propongo es una affirmative action de la doctrina comparatista (no tengo muchas esperanzas en los constitucionalistas ${ }^{63}$ ) a favor del reequilibrio, y el abandono de una visión multicultural a favor de un verdadero interculturalismo, capaz de aceptar también vínculos provenientes del exterior y no sólo de conceder al lado de la propia religión de Estado los cultos admitidos, dentro de los límites de la ley.

Sin embargo, a diferencia de la filosofía occidental, que es antropocéntrica, las filosofías orientales, africanas y en general las culturas «chtonias» no lo son: «no comparten la creencia en la naturaleza aislada, atomista y competitiva del ser humano, ni en la naturaleza utilitarista del bomo economicus, ni en el modelo social de centrifugación y gravitación, ni en la naturaleza absolutamente racional del hombre, ni en la naturaleza laica del mismo, ni en la naturaleza idéntica de los géneros, ni en las libertades sin virtudes, ni en el enfoque materialista y hedonista de la vida» ${ }^{64}$. Están orientadas a componer las antítesis, a evitar el conflicto, a seleccionar al gobierno en base a principios distintos de la temporalidad de los cargos. La búsqueda de uno o más puntos de contacto se revela compleja.

Una Grundnorm compartida entre Occidente y Sur del mundo podría ser uno de los tres preceptos de Ulpiano, «boneste vivere», pero es demasiado genérico y subjetivo para ser vinculante y eficaz, como de hechos los otros dos, «alterum non laedere» y «suum cuique tribuere», en los cuales, además, aflora algo el individualismo jurídico. También, se revela por la misma razón insatisfactoria «armonía», que en sus diversas declinaciones aparece un elemento unificador de casi todas las culturas no occidentales. «Pacta sunt servanda» estructura cualquier sociedad en cualquier latitud y en cualquier época, pero, además de la generaldiad, está dominada por la

62 V. por ej. Núñez Torres, M.G., Cavazos Guajardo Solís, A., «El multiculturalismo en el régimen constitucional mexicano: análisis comparado de las constituciones federal y locales», Rev. gen. dir. pubbl. comp., n. ${ }^{\circ} 27,2020$.

63 Explico las razones en «Comparación y globalización (las categorías del Derecho civil y el parasitismo metodológico de los constitucionalistas en el estudio del Derecho comparado)», GonzÁlez PÉREZ, L.R., Valadés, D. (eds.), El Constitucionalismo Contemporáneo, Unam-Iij, México, 2013, p. 265 ss., y en Teoría y modelos de la comparación. Ensayos de Derecho constitucional comparado, Olejnik, Santiago de Chile, 2016, p. 21 ss.

64 Marquardt, B., Historia constitucional comparada de Iberoamérica. Las seis fases desde la Revolución de 1810 basta la transnacionalización del siglo XxI, Ibañez, Bogotá, 2016, p. 39. 
política y las excepciones (basta pensar en la Universidad), además del conflicto con la exigencia de cambio.

Por tanto, es necesario situarse en un nivel menos general y más específico para encontrar, además de los otros elementos que dividen, los que unen y participan de más culturas jurídicas. Excluyo ahora mismo, por las razones mencionadas, que «derechos» y «dignidad» representen elementos básicos para culturas distintas de la occidental, así como no lo representa «deber» —aunque esté frecuentemente presente en el derecho chtonio- para la euro-atlántica.

Es necesario entonces discernir los componentes necesarios, irrenunciables en cada cultura (los «elementos determinantes», diría Constantinesco ${ }^{65}$ ), de los mediables, y sobre éstos intentar la edificación de un núcleo compartido.

Una oportunidad nada despreciable la ofrece el hecho de que las tradiciones jurídicas incorporan casi todos los valores/principios de los que hemos hablado hasta ahora: los derechos también están presentes en el Islam y en la cultura indígena, los deberes en occidente; la armonía podría declinarse en parte en la racionalidad occidental, la deferencia en el concepto de orden y seguridad, etc. La naturaleza ha hecho su aparición en el constitucionalismo occidental, aunque también de modo instrumental al antropocentrismo, el útil permea todas las sociedades; y así sucesivamente. La diferencia está en su axiología, en los criterios de preeminencia ${ }^{66}$.

Se trata entonces de buscar los elementos comunes, para ponerlos en un orden reequilibrado, hasta el límite del núcleo irrenunciable. Se trata de erosionar sus fronteras, utilizando lógicas débiles y categorías fuzzy, respetando los núcleos respectivos, pero permitiendo las superposiciones en las franjas exteriores. En definitiva, se trata de extraer de estas franjas uno o más elementos básicos/ determinantes compartidos, distintos de la dignidad y de los derechos, que por el contrario no son compartidos, para identificar un principio común, o más principios comunes, que actuén de directriz igualitaria de las culturas, en lugar de ese impuesto hasta ahora por la preeminencia cultural euro-atlántica.

Un breve análisis - forzosamente muy aproximado y para líneas muy largas- de algunas características de las principales legal traditions no occidentales pueden ser de ayuda.

\section{Islam: religión, obediencia, pero también familia, comunidad, caridad}

Partiendo de la cultura jurídica que en la communis opinio es considerada la más lejana y hostil al mundo occidental, la islámica, como explica M. Oliviero, «la mayoría de los musulmanes que toman el nombre de «sunnittas» [...]

65 Constantinesco, J.L., Einführung in die Rechtsvergleichung, I, Rechtsvergleichung, Heymanns, Köln, 1971; Die rechtsvergleichende Methode, II, Rechtsvergleichung, Heymanns, Köln, 1972.

66 El libro de referencia sobre las tradiciones es GLENN, H.P., Legal traditions of the World: Sustainable Diversity, Oxford U.P., Oxford, 2000. 
reconocen —como casi todos los musulmanes - los «cinco pilares de la sabiduría» (es decir, la profesión de la fe en Alá, la oración pública y privada, la obligación de la caridad, el ayuno anual en el Ramadam y la peregrinación a la Meca); pero, en particular, al determinar los comportamientos y las prescripciones de los fieles, incluyen la obligatoriedad de la obediencia a quien detenta la autoridad estatal. No obstante, para los sunnitas, la autoridad no puede interpretar el Corán o la Sunna para asumir una decisión política. Es en esto en lo que se diferencian los sunnitas de los chiitas [...], y sostienen que el liderazgo del Islam radica en la sucesión de los guías espirituales (imam). El imam puede tener o no un poder temporal, pero en cualquier caso se considera inspirado por Dios. Cuando detenta también el poder temporal, su autoridad espiritual — como demuestra la revolución Khomeinista de Irán en 1979 - genera una gestión hierocrática del poder. De forma distinta, los sunnitas no aceptan esta concepción y tienden a distinguir el poder espiritual de aquel temporal ${ }^{67}$.

Entre las bases que se pueden compartir con oltras culturas — tendiendo en cuenta la versatilidad del Islam, y aparte de la obediencia - se señalan la caridad, los vínculos solidarios (con repercusión en la economía y el sistema bancario ${ }^{68}$ ), y especialmente la familia: «El derecho islámico no se dirige al individuo, sino a la familia» —afirma drásticamente Losano ${ }^{69}$.

\section{Asia: armonía, deber, conciliación, bien común}

«En el nivel teórico y filosófico, los «valores asiáticos» incorporan principalmente las virtudes cardinales del confucianismo, hinduismo y otras concepciones filosóficas y religiosas: la primacía de los intereses colectivos sobre los individuales; la necesidad de garantizar la armonía social, incluso a costa de sacrificar las expectativas del individuo; la prevalencia de los intereses de la familia, la comunidad, la nación; el respeto por el orden y la estabilidad; el valor de la sobriedad y el ahorro; la disposición a sacrificarse por el bien de la comunidad; la renuncia al beneficio presente en vista de un beneficio futuro» ${ }^{70}$.

67 Oliviero, M., «Voz Derecho islámico», en Pegoraro, L. (ed.), Glosario de Derecho Público Comparado, Ferrer Mac-Gregor, E.,. Nuñez, M., Astudillo, C., Enríquez Fuentes, G.,. Torres Estrada, P., Porrúa, México, 2012, p. 122.

68 Nonne, L., «Il prestito ad interesse nel diritto islamico tra solidarietà e profitto», PAPA, M., PICCinelli, G.M., Scolart, D. (eds.), Il libro e la bilancia. Scritti in memoria di Francesco Castro, 2 vols, Esi, Napoli, 2011, II, p. 831 ss.; PETRUCCI, A., Radici storiche dei modelli giuridici nelle regole relative alla determinazione del corrispettivo in denaro di alcuni progetti di unificazione del diritto contrattuale, ivi, II, p. 949 ss.; PICCINELLI, G.M., La finanza islamica tra crisi globale e innovazione: la prospettiva europea, ivi, II, p. 977 ss.

69 Losano, M.G., I grandi sistemi giuridici. Introduzione ai diritti europei ed extraeuropei, Laterza, RomaBari, 2000, p. 336.

70 Ehr-Soon TAY, A., «I «valori asiatici» e il rule of law», en Costa, P., Zolo, D. (eds.), Lo Stato di diritto. Storia, teoria e critica, Feltrinelli, Milano, 2002, p. 693 ss. Sobre los valores asiáticos, v. también SENN, A., Human Rights and Asian Values, Carnegie Council on Ethics and Int. Affairs, New York, 1997; GropPI, 
En la perspectiva confuciana, el hombre que tiene la intención de cultivar las virtudes individuales sólo tiene un camino por recorrer: el del cumplimiento de los deberes y responsabilidades que se derivan de las relaciones con otras personas. En otras palabras, solo a través del cumplimiento de las obligaciones mutuas de los miembros de la comunidad, cada persona es plenamente consciente de su propia personalidad $»^{71}$.

También otras concepciones filosóficas comparten bases similares. El dharma hinduista «incluye aquel conjunto de reglas y comportamientos a los que el individuo debe aspirar para estar en armonía con el orden cósmico. El mismo no contempla una regla uniforme y válida para todos, pues puede variar dependiendo de la posición que tenga el individuo en la sociedad, en la comunidad religiosa, o en la casta» ${ }^{72}$.

Incuso en Japón - a pesar de la aparente occidentalización del derecho público- permanece la aversión por el conflicto, que concretamente se traduce en la propensión a recurrir a métodos alternativos de solución de las controversias, como los procedimientos de conciliación y arbitraje. «La natural consecuencia de esto ha sido también en la época contemporánea, el modesto recurso a los Tribunales y al sistema judicial tradicional, salvo en los casos en que las otras rutas alternativas de resolución sean ineficaces» ${ }^{73}$. Otra consecuencia es la diferente percepción de los derechos, ya que conceptos como «derecho subjetivo», «fundamental», «humano», etc., son occidentales y no tienen relación con la cultura japonesa $\mathrm{a}^{74}$.

De acuerdo con los valores asiáticos, la concepción prevalente en Asia sobre la condición del hombre se concilia mal con los derechos humanos. La tradición asiática pone el acento sobre los deberes que incumben a los individuos respecto de la colectividad; ello no es conciliable con la visión occidental de los derechos

T., «Costituzioni senza costituzionalismo? La codificazione dei diritti in Asia agli inizi del XXI secolo», Pol. dir., n. ${ }^{\circ}$ 2, 2006, p. 187 ss.; Groppi, T., Piergigli, V., Rinella, A. (eds.), Asian Constitutionalism in Transition: A Comparative Perspective, Giuffrè, Milano, 2008.

71 Pegoraro, V.L., Rinella, A., Sistemas constitucionales, cit., vol. A, p. 179 s. Por esta razón resulta difícil delinear, en un ordenamiento permeado por los trazos del confucianismo — como, por ej., los de China, Laos y Vietnam-, una posición jurídica subjetiva individual claramente separada de la colectividad. Por el contrario, la sociedad china, que durante mucho tiempo mantuvo una estructura feudal, todavía presenta hoy trazos de una dimensión jerárquica de las relaciones, en lugar de igualitaria. Combinando esta condición con la histórica ausencia de una tradición democrática y la influencia del confucianismo, se deriva que la conciencia de los propios derechos y libertades individuales no se encuentra en el modo de pensar de la población china. Para un perfil teórico sobre confucianismo y derecho público: Kıм, S., Public Reason Confucianism: Democratic Perfectionism and Constitutionalism in East Asia, Cambridge U.P., Cambridge, 2017.

72 Amirante, D., «Voz Derecho hindú y derecho indio», en Pegoraro, L. (ed.), Glosario de Derecho Público Comparado, cit., p. 117 s.

73 Sasso, F., Lo Coco, D., Giappone, cit., p. 43, y sobre todo Haley, J.O., The Myth of the Reluctant Litigant, en YANAGIDA, Y., et al. (eds), Law and Investments in Japan, Harvard U.P., Cambridge-London, 1995, p. 475 ss. Cfr. también PorT, K.L. (ed.), Comparative Law and the Legal Process in Japan, Carolina Acad. Press, Durham, 1996.

74 Véase Bertolini, E., La tutela dei diritti fondamentali in Giappone, Jovene, Napoli, 2011. 
humanos basada en el individualismo. De ahí se deriva que en la prospectiva de gobierno el desarrollo económico que puede suponer un avance para el conjunto de la comunidad prevalezca claramente sobre el respeto a la tutela de los derechos civiles y políticos; un gobierno burocrático y autoritario se presenta más funcional respecto a la consecución del bienestar colectivo» ${ }^{75}$.

Además de la «armonía», los conceptos de «deber», «orden moral», «bien de la comunidad» (y «útil») adquieren un significado distinto del occidental, donde aparecen como elementos fungibles y no determinantes. Sin embargo, no son en absoluto extraños a la western legal tradition, en sus formas cristiana, liberal y socialista. Por otro lado, los derechos individuales permanecen desapercibidos, ejercitables en cuanto compatibles con los otros valores.

\section{3. África: deber, pertenencia, comunidad, naturaleza}

Hasta el cambio de milenio, África no consigue trasladar a las constituciones su gran patrimonio espiritual y hacer efectivas las visiones políticas ancladas en las tradiciones nativas, a pesar de algunas tentativas en este; cuando menos las referencias al mismo, que a veces se dan, no prosperan.

Me refiero al Humanismo de K. Kaunda (primer Presidente de Zambia), cuya ideología se basaba en la plena libertad del hombre africano, en su bienestar (entendido en el sentido no material) y en su dignidad; al Ujamaa de J. Nyerere (primer Presidente de Tanzania), basado en la idea de la «antisocialidad» de la acumulación de riqueza, y los principios de solidaridad entre los ciudadanos, de ayuda mutua y de igualdad económica además de política: valores, todos ellos, presentes en la sociedad africana tradicional anterior a la colonización ${ }^{76}$; por último, el Conciencismo y Panafricanismo del gran leader de Ghana, K. N'krumah, basado en la concepción comunitaria de África tradicional, la conciencia humana y especialmente la africana. Para derrotar al capitalismo y anular esta mentalidad, N'krumah niega la necesidad de la lucha de clases, debido a la característica comunitaria de la sociedad africana, presente mucho antes de la colonización ${ }^{77}$.

Tales filosofías germinan del concepto africano de fraternidad (ubuntu), que - como explica M. Nicolini- permite «elaborar una nueva tradición jurídica donde el postcolonial discourse incorpora principios, valores, conceptos del derecho

75 Pegoraro, L., Rinella, A., Sistemas constitucionales, cit., vol. A, p. 180.

76 KPALAINGU KADONY, N., Une introduction aux relations internationales africaines, L'Harmattan, Paris, 2007, p. 97.

77 Sobre las influencias filosóficas, espirituales y religiosas en el pensamiento africano, y su influencia más significativa sobre los programas políticos de los leader antes, durante y con posterioridad al proceso de descolonización v. (en ed. italiana) Nkafu Nkemnkia, M., Il pensare africano come «Vitalogia», Città Nuova, Roma, 1997; ID., Prospettive di filosofia africana, Edizioni Associate, Roma, 2001; Id., Il divino nella religione tradizionale africana. Un approccio comparativo ed ermeneutico, Città Nuova, Roma, 2011. 
tradicional según narraciones que seguramente tienen un estilo à l'européenne, pero promueven el desarrollo de la experiencia jurídica comunitaria africana según directrices autónomas de las eurocéntricas y coloniales».

Estos valores se resumen, por ej., en el preámbulo de la nueva constitución de Madagascar, que recuerda, entre otros, a la creencia en Dios, Supremo Creador (Andriamanitra Andriananabary), la protección de la biodiversidad, las estructuras de gobierno tradicionales locales, la promoción de una sociedad que pueda vivir en armonía y en el respeto del otro, y sepa revalorizar «la richesse et (...) dynamisme de ses valeurs culturelles et spirituelles à travers le «fanaby maba-olona» (principio de existencia)», encontrando «son originalité, son authenticité et sa malgachéité (...) en conservant ses valeurs et principes fondamentaux traditionnels basés sur le fanaby malagasy qui comprend «ny fitiavana, ny fihavanana, ny fifanajàna, ny fitandroana, ny aina», et privilégiant un cadre de vie permettant un «vivre ensemble» sans distinction de région, d'origine, d'ethnie, de religion, d'opinion politique, ni de sexe». Finalmente, las estructuras comunitarias básicas — las sedes decisorias (Fokonolona) organizadas en aldeas (Fokontany) — constituyen «un marco de vida, de emancipación, de intercambio y de concertación de los ciudadanos»

Como recuerda $\mathrm{R}$. Toniatti ${ }^{78}$, las peculiaridades típicas del derecho chtonio «hacen que éste no se agote en una dimensión propia y distinta de la acción humana (el derecho, precisamente, distinto de la política, de la economía, de la moral, de la religión) pero está presente de forma indiferenciada en el interior de la generalidad de la experiencia de la vida cotidiana. La cosmogonía indígena produce su propio derecho, un derecho originario y original, un derecho equivalente a la ley del equilibrio natural, un derecho que, por lo tanto, no pertenece al hombre más de lo que pertenece a la tierra, incluso a la naturaleza en general, un derecho del que el hombre no puede disponer porque no le pertenece, pero al que debe adaptarse, porque es el hombre el que pertenece al derecho en la medida en que el derecho sea uno con la ley natural».

También por África prevalecen la naturaleza, los valores comunitarios, la familia y las pertenencias, mientras que los derechos son sólo la otra cara de los deberes.

\section{América Latina, un melting pot: valores occidentales, naturaleza, y buen vivir}

América Latina, de manera distinta a Asia y África, «no rechaza todos los valores (o si quieren disvalores) de la cultura occidental; mejor, sólo la percepción

78 Toniatti, R., «La razionalizzazione del «pluralismo giuridico debole»: le prospettive di un nuovo modello giuridico e costituzionale nell'esperienza africana», CALAmo Specchia, M. (ed.), Le trasformazioni costituzionali del secondo millennio. Scenari e prospettive dall'Europa all'Africa, Maggioli, Sant'Arcangelo di Romagna, 2016, § 3. 
indígena puede ser paragonada a las culturas africanas o asiáticas, pero por lo demás el «sistema» se propone como gran elemento de reequilibrio entre culturas tan distintas: el nuevo constitucionalismo latinoaméricano aparece entonces también como un mestizaje cultural, que traduce a nivel jurídico el mestizaje «físico» que caracteriza buena parte del continente» ${ }^{79}$. Incorpora de hecho al contenedor formal «occidental», y al lado de instituciones sustanciales de su tradición jurídica, los pilares de la tradición indígena.

En la propuesta jurídica y cultural que patrocina esta incorporación, M. Carducci escribe que «como alternativa a la centralidad del Estado — con su invariablemente unilateral invención de los "ciudadanos" y de sus "extranjeros" y del "contrato social" de subordinación a un poder "necesario"- el nuevo constitucionalismo legitima un verdadero y propio "contrato social” con la naturaleza, madre de la humanidad». «La naturaleza ya no es identificada como "objeto" de apropriación, exploración, preservación. No: se convierte en el sujeto que nutre y alimenta los seres humanos y por tanto a la sociedad. De "lugar" de la sociedad (ubi societas), finalmente se emancipa a la fuente jurídica primaria de la sociedad misma: la "bipótesis de Gaia", como se ha definido en memoria de la diosa griega, de la cual no puede sino derivar la Constitución como norma jurídica de garantía de aquélla "hipótesis" ${ }^{80}$.

«El "giro biocéntrico" — añade - mira al Estado del buen vivir y la vertiente programática constitucional se traduce en un Estado "ecológicamente responsable": ama qbilla, ama llulla, ama suwa (no tengas prejuicios, no mientas, no robes a otros), suma qamaña (vivir bien), ñandereko (promover la vida armoniosa), teko kavi (vivir la vida buena), ivi maraei (preservar una tierra sin el mal), qhapaj ñan (proceder por un camino de vida digna y noble) trazan los enunciados de esta normatividad ${ }^{81}$. O, si se prefiere: «la noción de pluriculturalidad, interculturalidad, la pachamama y el sumak kawsay» $^{82}$. La constitución ecuatoriana de 2008, recuerda Nilda Garay, «considera a dichos valores como deberes de la ciudadanía. Establece un conjunto

79 Me remito a mi trabajo «América Latina como categoría y objeto de comparación», Dir. pubbl. comp. eur., n. ${ }^{\circ}$ 1, 2018, p. 213, y en Pensamiento const., n. ${ }^{\circ}$ 22, 2017, p. 192; v. también Marquardt, B., Historia constitucional comparada de Iberoamérica. Las seis fases desde la Revolución de 1810 hasta la transnacionalización del siglo XXI, Ibañez, Bogotá, 2016, p. 56 ss., que deteniéndose en la influencia del «primer-tercier-mundismo hegemónico», y citando a G. Lomné, «Latinoamérica tiene un déficit de autoestima, intrevista de F. Tafur», en Un Periódico, n. ${ }^{\circ}$ 129, 2009, Bogotà, Unal, p. 9, se ocupa de «la mirada desdeñosa de las ciencias europeas y norteaméricanas hacia América Latina». V. además J.H. Elliotт (1970). The Old World and the New $1492-$ 1650, Cambridge, Cambridge. Un síntoma de este fenómeno denunciado por Marquard lo he destacado en un escrito reciente, debatiendo y criticando la «adoración» de la academia latinoaméricana a la academia europea y norteamericana, acogida sin una actitud crítica como «argumentum quoad auctoritatem»: v. Ruolo della dottrina, comparazione e legal tourism», en Diálogos de Saberes, n 43, 2015, p. 219 ss.

80 Carducci, M., La Costituzione come «ecosistema» nel nuevo constitucionalismo delle Ande, BaGNI, S. (ed.), Dallo Stato del bienestar allo Stato del buen vivir, cit., pp. 14 y 17.

81 Ibid.

82 Ávila Santamaría, R., El neoconstitucionalismo transformador. El estado y el derecho en la Constitución de 2008, Abya Yala, Quito, 2011, p. 17. 
de deberes y responsabilidades que incluye el principio "Ama killa, ama llulla, ama shwa. No ser ocioso, no mentir, no robar". La boliviana, incluye a estos tres valores dentro de un conjunto de principios expresando que el Estado "asume y promueve como principios ético-morales de la sociedad plural: ama qhilla, ama llulla, ama suwa (no seas flojo, no seas mentiroso ni seas ladrón)" ${ }^{83}$.

Los principios que son la base de esos nuevos modelos —observa S. Bagni«son aquellos de solidaridad y de respeto recíproco, de los cuales derivan no solamente derechos, personales y colectivos, sino también responsabilidades, hacia las generaciones futuras. Al final, se propone la superación de la idea de ciudadanía como status frente a la ciudadanía universal (art. 416, c. 6, const. Ecuador), por la cual la titularidad de los derechos constitucionales correspondería solamente a la base de la común pertenencia al género humano» ${ }^{84}$.

\section{5. ¿Y el occidente? Más allá de los derechos: egalité, fraternité, no taxation without representation}

En la concepción occidental, «El concepto de derecho subjetivo, absoluto o relativo, no es otro que la delimitación de un poder al que corresponde la sujeción, la obligación o el deber de uno o de todos los que entran en relación con el titular del derecho, dentro de los límites de la extensión normativa de aquél. Quizás este sistema intrísecamente conflictivo es la base del fracaso de las políticas multiculturales de muchos países, aplicadas en el plano jurídico a través de la creación de tantas comunidades separadas como son los posibles elementos que diferencian entre sí a los seres humanos: mujeres contra hombres, ciudadano contra extranjero, «heterosexual» contra «homosexual», blanco contra negro, etc.; o mediante la extensión, según el principio de igualdad formal, de la titularidad de los mismos derechos sin discriminaciones de raza, etnia, lengua, etc.» ${ }^{85}$.

Con las drásticasa palabras de G.U. Rescigno, «Para mi los derechos, esta orgía de derechos humanos, que coexisten tranquilamente con el vergonzoso derroche de

83 Garay Montañez, N., «Las concepciones no occidentales en el constitucionalismo latinoamericano: acerca de la categoría poder», Rev. gen. der. públ. comp., n. ${ }^{\circ} 27,2020$.

84 Bagni, S., Dal Welfare State al Caring State?, cit., p. 21. Base de referencia para el estudio del multiculturalismo es Kymlicka, W., Multicultural Citizenship, Oxford U.P., Oxford, 1995. Para una bibliografía esencial v. De Sousa Santos, B., Refundación del Estado en América Latina, Inst. Intern. de Der. y Sociedad, Lima, 2010; MARINI, G., «La costruzione delle tradizioni giuridiche ed il diritto latinoamericano», Riv. crit. dir. priv., n. ${ }^{\circ}$ 2, 2011, p. 163 ss.; VICIANO PASTOR, R. (ed.), Estudios sobre el nuevo constitucionalismo latinoamericano, Tirant, Valencia, 2012; BALDIN, S., ZAGO, M. (eds.), Le sfide della sostenibilità. Il buen vivir andino dalla prospettiva europea, Filodiritto, Bologna, 2014; Wolkmer, A.C., Fernandes, I., LiXA, M. (eds.), Constitucionalismo, descolonización y pluralismo jurídico en América Latina, Cenejus Nepe-Un. Fed. Santa Catarina, Aguascalientes-Florianopólis, 2015; LANNI, S., Il diritto nell'America Latina, cit.; BALDIN, S., Profili costituzionali del buen vivir andino, Giappichelli, Torino, 2019.

85 Bagni, S., Dal Welfare State al Caring State?, cit., p. 23. Sobre la centralidad de los derechos en la tradición jurídica occidental remito a Somma, A., Introduzione al diritto comparato, cit., p. 121. 
los ricos y la miseria y la desesperación de miles de millones de seres humanos, se asemejan a los que cierran el establo después de la huída de los bueyes: primero el sistema económico, a cuyo servicio están las constituciones y el derecho, crea y acrecienta dramáticas desigualdades, después llegan los derechos, impulsados por hombres de buena voluntad; casi siempre además, cuando estos derechos deben defender a los más pobres, se realizan, cuando se realizan, más por miedo de peligrosas rebeliones que por convicción de los poderosos de este mundo» ${ }^{86}$. Mientras S. Hopgood habla de «derechos humanos en el camino a la nada» ${ }^{87}$.

Estado, ciudadanía, derechos individuales (o fundamentales/humanos) no representan, sin embargo, las únicas coordenadas de lectura del derecho euro-atlántico, que también ha elaborado conceptos basilares compatibles con las otras culturas. El principio no taxation without representation expresaba -incluso dentro los límites de su ubicación histórica - la idea de un gobierno de las instituciones separado de la pertenencia estatal, de la ciudadanía; la egalité ha llevado a la sustitución del Estado liberal por el democrático y social, y todavía impregna, también en su versión «sustancial», los ordenamientos liberal-democráticos, y de manera predominante esa versión particular del derecho occidental que ha sido declinada en los ordenamientos socialistas. La fraternité — dejada al margen en gran medida por la reconstrucción formal de la ciencia jurídica- se traduce en el principio de solidaridad, que en ocasiones sirve de débil freno para el individualismo y los derechos que lo acompañan, hasta el punto de ser ahora invocada en recientes sentencias jurisprudenciales ${ }^{88}$.

Los derechos, entonces, no representan más que uno de los componentes —aunque el más expresivo del antropocentrismo occidental — de la western legal tradition en su vertiente constitucional, y es sólo porque son funcionales al desarrollo de la sociedad capitalista que se han convertido casi en el único elemento identificativo.

\section{CONCLUSIONES}

El conflicto entre los valores occidentales y el resto de valores se basa preponderantemente en filosofías readicalmente distintas, centradas respectivamente en el individuo y en la comunidad y la naturaleza, sobre derechos y sobre deberes;

86 Rescigno, G.U., La teoria costituzionale di LuigiFerrajoli, en Costituzionalismo.it, 3, 2008. El pasaje de Rescigno también es recordado por Mastromarino, A., «Il nuevo constitucionalismo latinoamericano: una lettura in prospettiva», Dir. pubbl. comp. eur., n. ${ }^{\circ} 2,2020$, p. 352.

87 Shopgood, S., «Human Rights on the Road to Nowhere», Hopgood, S., Snyder, J., Vinjamuri, L. (eds), Human Rights Futures, Cambridge U.P., Cambridge, 2017, p. 283 ss.

88 V. Conseil constitutionnel, Cédric H. de 6 de julio de 2018, y en la doctrina BorgetTo, M., La notion de fraternité en droit public français. Le passé, le présent et l'avenir de la solidarité, Lgdj, Paris, 1993; Sur le principe constitutionnel de fraternité, en Rev. dr. lib. fond., n. ${ }^{\circ} 14,2018$; BAGNI, S., "All you need [to compare] is love» revisited», Comp. L.R., n. ${ }^{\circ} 9$ (2), 2020, p. 54 ss. 
sobre imperativos externos y sobre vínculos morales. Y sin embargo, ninguna tradición excluye completamente a las demás, también por el efecto del tiempo: imposición por un lado, y de modo prevalente, prestigio por el otro, han llevado a la familiarización (en su mayoría unidireccional) del léxico jurídico de los países colonizadores y a una aceptación parcial de sus valores.

Hay —si bien axiológicamente dispuestos de manera diferenciada — valores compartidos, que en algunos casos ya han encontrado terreno de experimentación en nuevas formas de "constitucionalismo» sincretista que con esmero intenta afirmar lo que une más que lo que divide. Aparte del Islam, donde uno de los pilares está representado por la caridad, inspirada en las mismas bases de la fraternidad, basta pensar en las experiencias de la India, Nepal, Buthan en Asia ${ }^{89}$; pero sobre todo en África austral y donde el buen vivir latinoamericano, desde abajo (la sociedad civil) y en los Tribunales, y después en las elaboraciones constitucionales, se abrió paso a un modelo alternativo de convivencia, anclado en valores compartidos para todos ${ }^{90}$.

Se puede encontrar, utilizando una lógica fuzzy, un conjunto que involucre a los respectivos núcleos, superponiendo sólo las partes compartidas: derechos, deberes, armonía, religión, racionalidad, forma del derecho, etc., todos participan en el núcleo, pero la parte que se puede superponer en el diseño es pequeña y limitada ${ }^{91}$. Lo que se superpone mucho más es la «comunidad»: el occidente no la desconoce en absoluto, solo cambia su colocación, poniéndola en la cima de la escala de valores sólo cuando hay guerra y emergencia, anulando los derechos, mientras las otras culturas jurídicas la dejan siempre en el vértice; pero también el derecho occidental la enfatiza en la sociedad socialista y también a veces en aquella liberal.

Es la acentuación del elemento solidario, no el énfasis sobre los derechos fundamentales, o sobre el deber, lo que une Islam y dharma, y bexie, amae e ubuntu, y todos ellos con la egalité y la fraternité propias del derecho occidental, ya sea en sus

89 Menski, W.F., Hindu Law: Beyond Tradition and Modernity, Oxford U.P., New Delhi, 2003;. LINGAT, R., The Classical Law of India, Un. of California Press, Berkeley, 1973; ID., Les sources du droit dans le système traditionnel de l'Inde, Mouton \& Co., The Hague, 1967; Diwan, P., Modern Hindu Law, 9. a ed., Allahabad Law Agency, Allahabad, 1993. En la doctrina italiana destacan los estudios de D. AmirANTE, entre ellos «Il caleidoscopio del diritto indiano: percorsi di comparazione», Rev. gen. der. públ. comp., n. ${ }^{\circ} 14,2013$, p. 1 ss, Lo Stato multiculturale. Contributo alla teoria dello Stato dalla prospettiva dell'Unione Indiana, Bup, Bologna, 2014; La democrazia dei superlativi. Il sistema costituzionale dell'India contemporanea, Esi, Napoli, 2019, y ahora ViOLA, P., Costituzionalismo autoctono. Pluralismo culturale e trapianti giuridici nel subcontinente indiano, Bup, Bologna, 2020 .

90 Sobre la derivación no académica del nuevo constitucionalismo v. Viciano Pastor, R., MARTínEZ Dalmau, R., El nuevo constitucionalismo latinoamericano: fundamentos para una construcción doctrinal, Rev. gen. der. públ. comp., n. ${ }^{\circ}$ 9, 2011. Significativo el subtítulo del célebre libro de R. SAcco, Il diritto muto. Neuroscienze, conoscenza tacita, valori condivisi, il Mulino, Bologna, 2015.

91 BALDin, S., «Riflessioni sull'uso consapevole della logica fuzzy nelle classificazioni fra epistemologia del diritto comparato e interdisciplinarietà», Rev. gen. der. públ. comp., n. ${ }^{\circ}$ 10, 2012; D, The Fuzzy Logic and the Fuzzy Approach, en Bagni, S., Figueroa Mejía, G.A., Pavani, G. (eds), La ciencia del derecho constitucional comparado, cit., I, p. 129 ss. 
raíces cristianas, tanto en las liberales, como en las socialistas. La familia a su vez es un componente no sólo del derecho islámico, sino también de otras formas de producción (donde tal vez prevalecen otras pertenencias, tribales y/o de castas), y está lejos de ser marginal en el derecho occidental. La Naturaleza queda al margen de este circuito virtuoso, no porque occidente no contemple hoy su protección, sino por su diferente finalidad en las jerarquías de valores: en occidente para fines utilitarios, aunque no faltan aperturas y reconocimientos ${ }^{92}$, en el Sur del mundo como un elemento igual paritario, cuando no prioritario.

Es en estas realidades que se percibe el esfuerzo de construir «una forma de Estado más inclusiva de todos los componentes de la comunidad estatal y solidariamente respondiendo a las necesidades humanas de sus integrantes», que $\mathrm{S}$. Bagni llama «Caring State, esto es Estado que cuida, donde lo público cuida de lo privado, los individuos se cuidan los unos de los otros y entre ambos se cuidan del entorno en el que vivimos» ${ }^{93}$

Este esfuerzo está acompañado sólo de una parte minoritaria de la doctrina constitucionalista, que en sus principales componentes — sean neoiusnaturalistas o positivistas - permanecen ligadas a la idea colonial de exportar el núcleo occidental — los derechos humanos, o fundamentales_ _ desinteresándose de cualquier otro elemento, o más bien afirmando que también el respeto de las diversas culturas representa un derecho humano, imponendo fideísticamente sus propias pertenencias.

Reconduciendo todo a un problema de derechos de las personas y a la dignidad, olvida otras categorías. El hecho de que, según Forbes, en el mundo 2.153 personas posean más riqueza que 4,6 mil millones de personas, y sólo 8 hombres posean 426 mil millones de dólares, la misma riqueza que 3,6 mil millones de personas, no tiene nada que ver con los derechos humanos. El pecado original es que, mientras a Marco Polo le interesa tratar con Kubla Khan, abrir el camino de la seda, y es curioso, quiere aprender y no sólo enseñar, y no pretende ser mejor, a Robespierre y Lenin les interesan exigencias vastas, pero particulares (de clase), a las que atribuyen el carácter de universalidad. Fuera de la metáfora, es la diferencia entre derecho civil (que siempre ha existido en todas partes) y derecho constitucional (que está sólo donde ha llegado el constitucionalismo porque está enraizado en las exigencias económicas e históricas), entre sistemas jurídicos y normas supremas, constitucionales, y que a menudo se manifiesta como fe más que como ciencia ${ }^{94}$.

92 Bagni, S., Back to the Future: Building Harmony with Nature in the European Union by Learning from our Ancestors, BALDIN, S., DE VIDO, S., Environmental Sustainability in the European Union: Socio-Legal Perspectives, Eut, Trieste, 2020, p. 77 ss.; «From the Andes to the EU: Customary Law within the ecology of Law», Rev. gen. der. públ. comp., n. ${ }^{\circ}$ 26, 2019, p. 1 ss.; El aporte del derecho procesal constitucional al litigio estratégico sobre el cambio climático: comentarios a los casos Urgenda y Juliana, en Estupiñán ACHury, L., Storini, C., MarTíneZ Dalmau, R., De Carvalho Dantas, F.A., La Naturaleza como sujeto de derechos en el constitucionalismo democrático, Universidad Libre, Bogotá, 2019, p. 333 ss.

93 Bagni, S., Dal Welfare State al Caring State?, cit., p. 19 s.

94 Cfr. de nuevo Bussani, M., Il diritto dell'Occidente. Geopolitica delle regole globali, cit. 
La sociedad civil, la jurisprudencia y, a veces, el formante normativo (constitucional o legislativo) de África y América Latina (incluyendo la excepción cubana), y en parte Asia, parecen mucho más previsoras en la búsqueda de una receta jurídica que acompañe la mundialización del derecho: por una parte, imposición, a través de los derechos humanos en apoyo de la globalización económica y cultural; por otra, búsqueda de compartir (que hasta ahora no siempre ha sido satisfactoria).

Si bien es verdad que una parte del núcleo «occidental» (el ejercicio de los derechos) debe vincular a todos, también el occidente debería a su vez ser sometido a otros núcleos, o al menos comenzar a tomarlos en consideración. Como, en esencia, ha dicho la Corte Constitucional sudafricana, ¿por qué el ubuntu no debería representar un parámetro también para los blancos, si los blancos pretenden que los negros estén vinculados por la dignidad? De este modo, seguida de otras Cortes de área austral, ha incorporado las tradiciones en el corpus (occidental) de los parámetros constitucionales ${ }^{95}$. No de manera distinta lo han hecho algunas constituciones y parte de la jurisprudencia constitucional latinoamericana ${ }^{96}$, por lo que a la pregunta: «¿Pueden las soluciones acerca del balanceamiento del derecho tradicional y el de derivación estatal, cultura occidental y cultura indígena, armonía e individualismo, individuo, comunidad y naturaleza, elaboradas en América Latina, África y Asia, ser exportadas en lugares y regiones donde se plantean, aunque de forma distinta, problemas análogos de compatibilización?» pienso que se puede contestar: $«$ sí $^{97}$.

A. Somma nos recuerda que «el poder cuya protección requiere el sacrificio de la visión de parte, es aquel ligado a la profesionalidad que no raramente termina por expresarse en las formas que Alexis de Tocqueville pudo denunciar con palabras duras pero plenamente vigentes: "si se estudiara atentamente lo que ha sucedido en el mundo desde que los hombres conservan el recuerdo de los acontecimientos, se descubriría sin dificultad que, en todos los países civilizados, al lado de un déspota que manda, casi siempre se encuentra un jurista que legaliza y da sistema a las voluntades arbitrairas e incoherentes del primero" ${ }^{98}$.

La dominante doctrina constitucionalista, animada por nobles ideales (la tutela de los derechos) parece perder de vista los objetivos de libertad, igualdad, justicia y fraternidad que animan y están en la base de su credo, rechazando los criterios que no son los suyos propios y así acompañando la uniformación económica neo-liberal. Elabora y refuerza una ideología que, al lado de los criterios de legitimación de las fuentes, abre un camino a un ulterior criterio, de base

95 Nicolini, M., L'altra Law of the Land. La famiglia giuridica «mista» dell'Africa australe, Bup, Bologna, 2016.

96 Por ej. la colombiana: v. Estupiñán Achury, L., Hernández, C.A., Jiménez, W.G. (eds.), Tribunales y Justicia Constitucional. Homenaje a la Corte Constitucional Colombiana, Universidad Libre, Bogotà, 2017.

97 Pegoraro, L., «Imposición cultural, la búsqueda de denominadores comunes y el papel del "comparatista" en las revistas de derecho constitucional», en Rev. Academia Colombiana de Jur., n. ${ }^{\circ}$ 371, 2020, p. 411 ss.

98 A. Somma, Il diritto privato europeo e il suo quadro costituzionale di riferimento nel prisma dell' economia del debito, en S. Bagni, G. Figueroa Mejía, G. PAVAni (eds), La ciencia del derecho constitucional comparado, cit., I, p. 412. 
místico-laica, que condiciona a todos los demás (la tradición, la divinidad, la razón, el consenso, la voluntad política) ${ }^{99}$ y se sobrepone, dando legitimación al aplastante poder económico, precisamente a expensas de los derechos y la dignidad de las personas que se propone de defender y tutelar ${ }^{100}$.

TITLE: Against the colonial hiper-constitution of fundamental rights. In search of a shared intercultural core

AвSTRACT: The essay criticises legal 'Westernism', and challenges the universalistic approach to public/constitutional law based on fundamental/buman rights. To this extent, it highlights bow globalisation harshly confronts social, cultural, political, economic, and legal pluralism. After analysing common elements among different cultures and traditions, it suggests an alternative constitutional/transnational "bard core". The proposed new "hard-core" focuses on different values, i.e. community, solidarity, and fraternite as the funding elements of Western, as well as Eastern and Southern, legal traditions. In so doing, the essay rejects the 'orientalist' approach based on an allegedly Western Grundnorm, and avoids the theoretical —and potentially pragmatic_ imperialism of fundamental/buman rights and dignity.

RESUMEN: El ensayo critica el occidentalismo jurídico y denuncia el enfoque universalista del derecho público/constitucional basado en los derechos fundamentales/bumanos, en apoyo al ataque que la globalización desarrolla contra el pluralismo social, cultural, político, económico y jurídico. Se analizan los elementos que comparten varias culturas y tradiciones jurídicas, y sugiere una propuesta alternativa de «núcleo duro» constitucional/transnacional, centrado no sólo en el imperialismo de los derechos fundamentales/bumanos y la dignidad, Grundnorm del mundo occidental, sino en valores como la comunidad, la solidaridad y la fraternité, propios de occidente y de tradiciones juridícas orientales y del Sur del mundo.

KeY WORDS: Key-words: Legal Traditions, Pluralism, Human/Fundamental Rights, Westernalism, "Hard-core" values.

Palabras Clave: Culturas jurídicas, pluralismo, derechos humanos/fundamentales, occidentalismo, núcleo esencial.

FECHA DE RECEPCIÓN: 17.12.2020 FeCHA DE ACEPTACIÓN: 26.01.2021

99 Las referencias son a las categorías de la legitimación del poder elaboradas por A. Pizzorusso, Sistemi giuridici comparati, 2. ${ }^{a}$ ed., Giuffrè, Milano, 1998, p. 257 ss., que se hacen eco de las propuestas de J. VANDERLINDEn, Comparer les droits, Story-Scientia, Diegem, 1995, p. 334 ss. Éste — como lo recuerda A. SommA, Introduzione al diritto comparato, cit., p. 94- «moviéndose (...) de una noción de sistema jurídico liberado del requisito de la estatalidad, propone reagrupar el derecho a partir de la «fuente dominante», es decir del prevalente «modo de formulación del derecho», y de concentrarse sólo en un segundo tiempo en eventos como «la ideología o la técnica». De esta manera podemos distinguir: un «sistema consuetudinario» generado por el comportamiento de los miembros de la sociedad, un «sistema doctrinal» centrado en las reglas producidas por los académicos, un «sistema jurisprudencial» basado en los preceptos de los jueces, un «sistema legislativo» basado en órdenes formuladas por un vértice y un «sistema revelador» atribuible a una deidad».

$100 \mathrm{Si}$ el poder debe ser limitado, sólo queda confiar en la resistencia que interpone la estratificación secular de los otros criterios, no porque deban prevalecer, sino para que puedan combinarse y equilibrarse. Cfr. Amirante, D., «L'economia viaggia veloce, il diritto lento: note minime autobiografiche su comparatisti e globalizzazione», Bagni, S., Figueroa Mejía, G., Pavani, G. (eds.), La ciencia del derecho constitucional comparado, cit., I, p. 121 ss. 
